\title{
Design, synthesis and biological evaluation of Arylpiperazine-based novel Phthalimides: Active inducers of testicular germ cell apoptosis
}

\author{
ANIL K SINGH $^{\mathrm{a}}$, JITENDER K BHARDWAJ ${ }^{\mathrm{b}, *}$, ANA OLIVAL ${ }^{\mathrm{c}}$, YOGESH KUMAR $^{\mathrm{a}}$, \\ AVIJIT PODDER $^{\mathrm{d}}$, ANKUR MAHESHWARI $^{\mathrm{e}}$, RENUKA AGRAWAL $^{\mathrm{f}}, \mathrm{N} \mathrm{LATHA}^{\mathrm{d}}$, \\ BRAJENDRA K SINGH ${ }^{\mathrm{a}}$, HELENA TOMÁS ${ }^{\mathrm{c}}$, JOÃO RODRIGUES ${ }^{\mathrm{c}}$, \\ RAM KISHAN $^{\mathrm{g}}$, B RUPINI ${ }^{\mathrm{h}}$ and BRIJESH RATHI ${ }^{\mathrm{i}, *}$

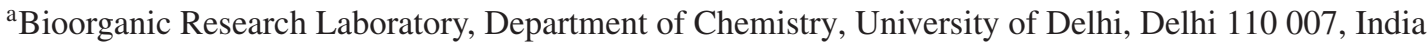 \\ ${ }^{\mathrm{b}}$ Reproductive Physiology Laboratory, Department of Zoology, Kurukshetra University, \\ Kurukshetra, Haryana 136 119, India \\ ${ }^{\mathrm{c}}$ CQM-Centro de Química da Madeira, MMRG, Universidade da Madeira, Campus da Penteada, \\ 9020-105 Funchal, Portugal \\ ${ }^{\mathrm{d}}$ Bioinformatics Infrastructure Facility, Sri Venkateswara College, University of Delhi, \\ Dhaula Kuan, New Delhi 110 021, India \\ e Department of Zoology, Zakir Husain Delhi College, University of Delhi, J L N Marg, \\ New Delhi 110 002, India \\ ${ }_{\mathrm{f}}^{\mathrm{f}}$ Department of Botany, Miranda House, ${ }^{\mathrm{g}}$ Department of Chemistry, University of Delhi, \\ Delhi 110 007, India \\ ${ }^{\mathrm{h}}$ School of Agriculture, Environmental Studies, Indira Gandhi National Open University, \\ New Delhi 110 068, India \\ ${ }^{i}$ Department of Chemistry, Hansraj College, University of Delhi, Malka Ganj, Delhi 110 007, India \\ e-mail: brijeshrathi@hrc.du.ac.in; jkbkuk@gmail.com
}

MS received 31 March 2016; revised 25 May 2016; accepted 30 May 2016

\begin{abstract}
Understanding of apoptosis or programmed cell death has provided the basis for novel therapeutics that has resulted in rationally designed anticancer strategies. Recently, inducers of apoptosis have been used in cancer therapy. In this work, we describe the role of chiral phthalimides functionalized with piperazines as potential apoptotic inducers. The listed twenty phthalimides were assessed for their in vitro apoptotic activity against testicular germ cells. All phthalimides showed a significant apoptotic response ( $\sim 39$ to $\sim 68 \%)$. TUNEL assay and acridine orange fluorescence staining were carried out to investigate the molecular mechanisms responsible for the cell death. Phthalimides exhibited substantial apoptotic induction following the intrinsic pathway mechanism. Studies advocated that the apoptotic induction was mediated through caspase- 9 , caspase3, JNK MAP kinase and tumor suppressor p53, which was accompanied by DNA fragmentation and nuclear condensation. Besides, the best five phthalimides regarding apoptotic action were evaluated for in vitro cytotoxic effects against CAL-72 and MCF-7 cancer cell lines. Compounds showed efficient killing of cancer cells. This discovery of functionalized phthalimides as apoptotic inducers would be highly valuable in understanding the mechanism of apoptosis at the molecular level and opens up new possibilities for therapeutic strategies.
\end{abstract}

Keywords. Phthalimides; apoptosis; molecular docking; aryl piperazine; cancer cells.

\section{Introduction}

Apoptosis or programmed cell death is an energy demanding obligatory process that involves the morphological alteration of tissues, DNA degeneration and cellular reduction. ${ }^{1-5}$ Apoptosis is highly helpful for the organisms to eliminate the unwanted and unnecessary

*For correspondence cells viz. senescent, damaged, genetically mutated, or virus-infected cells. In particular, it is important for controlling the unlimited cell proliferation that characterizes cancer, which is often a lethal disease. ${ }^{6-10}$ Caspases, a family of intracellular cysteine proteases play a significant role in the cellular processes of apoptosis, inflammation and necrosis. ${ }^{4,11}$ Two major pathways, namely extrinsic and intrinsic, have been identified as possible mechanistic processes of apoptosis. ${ }^{12}$ Several mediators such as TNF- $\alpha$ (tumor necrosis factor), Fas 
ligand (FasL), chemotherapy, radiation, etc., are potent inducers of apoptosis. A mechanistic view of apoptosis involves a cascade of initiator and effector caspases that are activated sequentially. The initiator caspases $(2$, 8,9 , and 10) are located on the upstream of the signaling cascade. However, executioner caspases $(3,6$, and 7 ) are positioned on the horizon of the cascade. Caspase 3 handles the splitting of many substrates such as polyADP ribose polymerase (PARP), a DNA repair enzyme that leads to an unavoidable cell death. ${ }^{13,14}$ Besides, caspase 3 induces the cleavage of inhibitors of caspase-activated DNAses (ICAD) and ultimately cleaves DNA. The activation of caspase 3 following mitochondrial pathways is considered as a critical tool for the development of anticancer drug-induced apoptosis. Mitogen-activated protein kinases (MAPKs) like JNK, p38, ERK respond to external stress and drugs. MAPKs handle the phosphorylation of the immediate early transcription factor for their respective genes like c-Jun and c-Fos. ${ }^{15}$

There is an urgent need for new proapoptotic therapeutic agents with novel modes of action, to broaden the scope of treatment and to overcome emerging drug resistance. Numerous cytotoxic molecules either natural or synthetic have been developed to target apoptotic cell death, an approach considered as crucial for the future development of anticancer agents. ${ }^{16-20}$ In recent years, several piperazine-based molecules have been reported to possess strong apoptotic activity on cancerous cells. ${ }^{21-28}$ Piperazine based small amides such as AK301 (I), have been stated to induce mitotic arrest and to increase ligand-dependent apoptosis in HT29 human colon cancer cells $\left(\mathrm{ED}_{50}: 115 \mathrm{nM}\right){ }^{21}$ Also, piperazine based alkyl compounds have been reported to cause apoptosis by inducing RhoB expression via ROS-mediated cAbl/p38 MAPK signaling. ${ }^{22}$ She and co-workers identified few piperazine derivatives, which potently induce caspase-dependent apoptosis in cancer cells. ${ }^{23}$ Benzothiazole-phthalimide (II) was identified as an apoptotic inducer to cancer cell lines following caspase-dependent and independent pathways. ${ }^{17}$ Thalidomide (III) ${ }^{29}$ possessing isoindoline skeleton is one of the most explored phthalimide molecules especially as an antiangiogenic agent. ${ }^{30,31}$ Moreover, some reports advocate thalidomide and its derivatives as potential anti-cancer agents. ${ }^{32,33}$ Shiheido et al., demonstrated TC11 (IV) as an inducer of caspases 3, 8 and PARP. ${ }^{34}$ Apoptotic inducers attain much attention due to their potential role in cancer chemotherapy. ${ }^{35,36}$

Hence, the discovery of apoptotic inducers is one of the natural choices to secure potential anticancer agents. To achieve effective new molecules, herein we present new phthalimides of chemical diversity, which have been designed by taking into account the vital role of I-V as anticancer agents (Figure 1). New phthalimides (3a-t) possessing piperazines were prepared and tested for their in vitro apoptotic activity on testicular germ cells of goat (Capra hircus) as well as for their cell viability. The screening advocated phthalimide $\mathbf{3 j}$ as the most potential apoptotic inducer following the intrinsic pathway mechanism. The apoptotic induction was mediated through caspase-9, caspase-3, JNK MAP kinase and tumour suppressor $\mathrm{p} 53$, which was accompanied by DNA fragmentation and nuclear condensation. To the best of our knowledge, this is the first study on phthalimides functionalized with arylpiperazines as apoptotic inducers, particularly on a domestic animal.

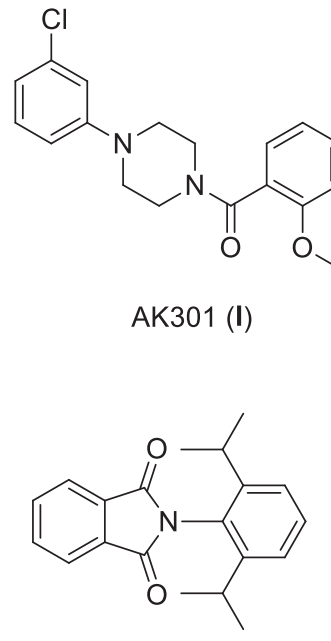

TC11 (IV)<smiles>O=C1c2ccccc2C(=O)N1c1nc2ccc(OC(F)(F)F)cc2s1</smiles>

Benzothiazole containing Phthalimide (BP) (II)<smiles>O=C1CCC(N2C(=O)c3ccccc3C2=O)C(=O)N1</smiles>

Thalidomide (III)

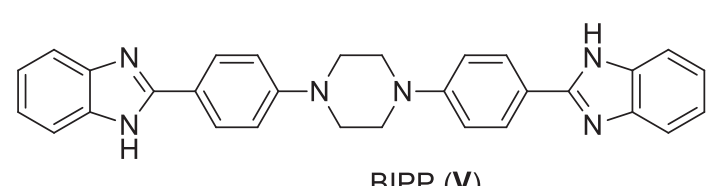

Figure 1. Structure of compounds having apoptotic and anticancer activity. 


\section{Materials and Methods}

\subsection{Synthesis and characterization of the phthalimides}

2.1a Reagents, equipment and other general issues: Chemicals and solvents used in the experiment were commercially available and used as received. All $N$ substituted piperazine derivatives were purchased from Sigma-Aldrich, USA. Homogeneity/purity of all the products was assayed by thin-layer chromatography (TLC) on alumina-coated plates (Merck). Product samples in chloroform $\left(\mathrm{CHCl}_{3}\right)$ were loaded on TLC plates and developed in ethylacetate/petroleum ether $(1: 1$, $\mathrm{v} / \mathrm{v})$. When slight impurities were detected by iodine vapour/UV light visualization, compounds were further purified by chromatography on silica gel columns (100-200 mesh size, CDH). Melting points were determined on a Büchi M-560 melting point apparatus. Infrared (IR) spectra were recorded in $\mathrm{KBr}$ pellets using a Perkin-Elmer Fourier Transform-IR spectrometer (Spectrum RXI-Mid IR), whereas ${ }^{1} \mathrm{H}$ and ${ }^{13} \mathrm{C}$ nuclear magnetic resonance (NMR) spectra were recorded in $\mathrm{CDCl}_{3}$ medium on a JNM ECX-400P (JEOL, USA) spectrometer with tetramethylsilane (TMS) as internal reference. Absorption frequencies ( $v)$ are expressed in $\mathrm{cm}^{-1}$, chemical shifts in ppm ( $\delta$-scale) and coupling constants $(J)$ in Hz. Splitting patterns are described as singlet (s), doublet (d), triplet (t), quartet (q) and multiplet $(\mathrm{m})$. High-resolution EI-mass spectra were performed with a resolution of 10,000 on KRATOS MS50TC, University of Leuven (KU Leuven), Celestijnenlaan 200F, 3001 Leuven, Belgium. The optical rotation of all phthalimides was measured using Autopol III Polarimeter, Rudolf research analytical. Fluorescence studies were made by using Fluorescence microscope (Olympus, Japan) using 500-525 nm filters.

\section{1b General procedure for synthesis of phthalimides} (3a-t): To the solution of $N$-phthaloyl-L-amino acid $(0.4 \mathrm{mmol})$ in dichloromethane $(20 \mathrm{~mL})$, 1-ethyl-3-(3dimethylaminopropyl) carbodiimide hydrochloride, EDC. $\mathrm{HCl}(0.6 \mathrm{mmol})$ and triethylamine, TEA $(1.6 \mathrm{mmol})$ were added and the contents were stirred at $0^{\circ} \mathrm{C}$ for $15 \mathrm{~min}$ to secure homogenous reaction mixture. Subsequently, HOBt $(0.6 \mathrm{mmol})$ was added to the reaction mixture and stirring was continued for another $15 \mathrm{~min}$ at the same temperature. N-substituted piperazine derivative $(0.48 \mathrm{mmol})$ was added and reaction mixture was stirred for $24 \mathrm{~h}$ at room temperature. The solvent was evaporated under reduced pressure and the reaction contents were extracted with ethylacetate and water. The organic layer was collected separately, concentrated under reduced pressure and purified by column chromatography (ethylacetate/petroleum ether, 4:6). Phthalimides (3a, 3e, 3g, 3i and 3m) have been previously prepared by our team and their structural aspects were investigated for nonlinear optical property. ${ }^{37}$ All the compounds were characterized by spectroscopic tools and the corresponding spectroscopic data are described in supporting information.

$2.1 \mathrm{~b} 1$ (S)-2-(1-(4-(4-bromobenzyl)piperazin-1-yl)-1oxo-3-phenyl propan-2-yl)isoindoline-1,3-dione $(3 \mathrm{~b})$ : The title compound was obtained as white solid having yield $72 \%$; M.p.: $125-127^{\circ} \mathrm{C}$; $[\alpha]_{\mathrm{D}}{ }^{26}-150.6(c=0.2$ in ethylacetate); FTIR $(\mathrm{KBr}) v_{\max }\left(\mathrm{cm}^{-1}\right): 3026,2882$, 2826, $1712(\mathrm{C}=\mathrm{O}$, imide $), 1663(\mathrm{C}=\mathrm{O}$, amide $), 1426$, 1384, 996, 719; ${ }^{1} \mathrm{H}$ NMR $\left(400 \mathrm{MHz}, \mathrm{CDCl}_{3}\right) \delta 7.76-$ 7.73 (m, 2H, H-4, H-7), 7.69-7.66 (m, 2H, H-5, H-6), $7.40\left(\mathrm{~d}, J=8.05 \mathrm{~Hz}, 2 \mathrm{H}, \mathrm{H}-3^{\prime \prime \prime}\right), 7.17-7.11(\mathrm{~m}, 7 \mathrm{H}$, Ar-H), 5.22 (dd, $\left.J=5.86,9.32 \mathrm{~Hz}, 1 \mathrm{H}, \mathrm{H}-2^{\prime}\right), 3.79-$ 3.41 (m, 8H, H-3', H-1'"', $\left.\mathrm{H}-2^{\prime \prime}, \mathrm{H}-6^{\prime \prime}\right), 2.38$ (m, 4H, $\left.\mathrm{H}-3^{\prime \prime}, \mathrm{H}-5^{\prime \prime}\right) \mathrm{ppm} ;{ }^{13} \mathrm{C}$ NMR $\left(100 \mathrm{MHz}, \mathrm{CDCl}_{3}\right): \delta$ $167.59(\mathrm{C}=\mathrm{O}), 166.72(\mathrm{C}=\mathrm{O}), 136.90,134.15,131.49$, 131.29, 130.82, 129.06, 128.51, 126.85, 123.43, 61.71, 60.34, 52.40, 44.83, 42.00, 35.03 ppm; HRMS m/z calculated $[\mathrm{M}]^{+}$for $\mathrm{C}_{28} \mathrm{H}_{26} \mathrm{BrN}_{3} \mathrm{O}_{3}^{+}$531.1158; found: 531.1150 .

$2.1 \mathrm{~b} 2$ (S)-2-(1-(4-(4-bromobenzyl)piperazin-1-yl)-3methyl-1-oxobutan-2-yl)isoindoline-1,3-dione $(3 \mathrm{c})$ : The title compound was obtained as white solid having yield $62 \%$; M.p.: $108-110^{\circ} \mathrm{C} ;[\alpha]_{\mathrm{D}}{ }^{26}-79.3(c=0.2$ in ethylacetate); FTIR (KBr) $v_{\max }\left(\mathrm{cm}^{-1}\right) 2963,2927$, $1716(\mathrm{C}=\mathrm{O}$, imide $), 1654(\mathrm{C}=\mathrm{O}$, amide $), 1466,1382$, 1070, 720; ${ }^{1} \mathrm{H}$ NMR $\left(400 \mathrm{MHz}, \mathrm{CDCl}_{3}\right) \delta$ 7.78-7.76 (m, 2H, H-4, H-7), 7.70-7.65 (m, 2H, H-5, H-6), $7.35\left(\mathrm{~d}, J=8.05 \mathrm{~Hz}, 2 \mathrm{H}, \mathrm{H}-3^{\prime \prime \prime}\right), 7.12-7.10(\mathrm{~m}, 2 \mathrm{H}$, $\left.\mathrm{H}-2^{\prime \prime \prime}\right), 4.55\left(\mathrm{~d}, J=10.25 \mathrm{~Hz}, 1 \mathrm{H}, \mathrm{H}-2^{\prime}\right), 3.61(\mathrm{~s}$, 2H, H-1"'"') 3.50-3.41 (m, 4H, H-2", H-6"), 3.03-3.00 (m, 1H, H-3'), 2.42-2.22 (m, 4H, H-3", H-5"), 0.97 $\left(\mathrm{d}, J=6.59 \mathrm{~Hz}, 3 \mathrm{H}, \mathrm{H}-4^{\prime}\right), 0.80(\mathrm{~d}, J=6.59 \mathrm{~Hz}$, $3 \mathrm{H}, \mathrm{H}-4$ ') ppm; ${ }^{13} \mathrm{C} \mathrm{NMR}\left(100 \mathrm{MHz}, \mathrm{CDCl}_{3}\right): \delta$ $167.73(\mathrm{C}=\mathrm{O}), 166.65(\mathrm{C}=\mathrm{O}), 134.30,131.57,131.30$, $130.94,130.90,123.56,61.67,56.14,52.82,52.47$, 29.66, 27.52, 20.53, $19.13 \mathrm{ppm}$; HRMS $\mathrm{m} / \mathrm{z}$ calculated $[\mathrm{M}]^{+}$for $\mathrm{C}_{24} \mathrm{H}_{26} \mathrm{BrN}_{3} \mathrm{O}_{3}^{+}$483.1158; found: 483.1126 .

$2.1 \mathrm{~b} 32-((2 S, 3 S)-1-(4-(4-b r o m o b e n z y l)$ piperazin-1-yl)3-methyl-1-oxopentan-2-yl)isoindoline-1,3-dione (3d): The title compound was obtained as white solid having yield 69\%; M.p.: $101-103^{\circ} \mathrm{C} ;[\alpha]_{\mathrm{D}}{ }^{28}-13.7(c=0.2$ in ethylacetate); FTIR (KBr) $v_{\max }\left(\mathrm{cm}^{-1}\right)$ 2965, 2929 , 1713 ( $\mathrm{C}=\mathrm{O}$, imide), 1657 ( $\mathrm{C}=\mathrm{O}$, amide), 1434, 1383, 
1072, 722; ${ }^{1} \mathrm{H}$ NMR (400 MHz, $\left.\mathrm{CDCl}_{3}\right) \delta$ 7.78-7.76 (m, 2H, H-4, H-7), 7.68-7.63 (m, 2H, H-5, H-6), 7.36 $\left(\mathrm{d}, J=7.32 \mathrm{~Hz}, 2 \mathrm{H}, \mathrm{H}-3^{\prime \prime \prime}\right), 7.13\left(\mathrm{~s}, 2 \mathrm{H}, \mathrm{H}-2^{\prime \prime}\right), 4.67$ $\left(\mathrm{d}, J=10.25 \mathrm{~Hz}, 1 \mathrm{H}, \mathrm{H}-2^{\prime}\right), 3.57-3.41\left(\mathrm{~m}, 6 \mathrm{H}, \mathrm{H}-1^{\prime \prime \prime \prime}\right.$, H-2", H-6"), 2.86-2.79 (m, 1H, H-3'), 2.35 (m, 4H, H-3", H-5"), 1.33-1.41 (m, 1H, H-4'), 1.04-0.97 (m, $\left.1 \mathrm{H}, \mathrm{H}-4^{\prime}\right), 0.92$ (d, $\left.J=5.86 \mathrm{~Hz}, 3 \mathrm{H}, \mathrm{H}-6^{\prime}\right), 0.79$ (t, $\left.J=7.32 \mathrm{~Hz}, 3 \mathrm{H}, \mathrm{H}-5^{\prime}\right) \mathrm{ppm} ;{ }^{13} \mathrm{C}$ NMR $(100 \mathrm{MHz}$, $\left.\mathrm{CDCl}_{3}\right) \delta 167.82(\mathrm{C}=\mathrm{O}), 166.98(\mathrm{C}=\mathrm{O}), 134.27$, 131.63, 131.34, 131.27, 131.08, 131.01, 123.53, 61.64, 54.88, 52.87, 33.71, 33.04, 25.29, 16.47, 15.14, 11.40, $10.58 \mathrm{ppm}$; HRMS $\mathrm{m} / \mathrm{z}$ calculated $[\mathrm{M}]^{+}$for $\mathrm{C}_{25} \mathrm{H}_{28}$ $\mathrm{BrN}_{3} \mathrm{O}_{3}^{+}$497.1314; found 497.1293.

2.1b4 (S)-2-(1-(4-(4-fluorobenzyl)piperazin-1-yl)-1-oxo3-phenyl propan-2-yl)isoindoline-1,3-dione (3f): The title compound was obtained as white solid having yield $65 \%$; M.p.: $131-133^{\circ} \mathrm{C} ;[\alpha]_{\mathrm{D}}{ }^{27}-137.3(c=0.2$ in ethylacetate); FTIR $(\mathrm{KBr}) v_{\max }\left(\mathrm{cm}^{-1}\right) 3058,2916$, $1713(\mathrm{C}=\mathrm{O}$, imide), $1661(\mathrm{C}=\mathrm{O}$, amide $), 1429,1384$, 1225, 720; ${ }^{1} \mathrm{H}$ NMR (400 MHz, $\left.\mathrm{CDCl}_{3}\right) \delta$ 7.71-7.69 (m, 2H, H-4, H-7), 7.63-7.61 (m, 2H, H-5, H-6), 7.21$7.19\left(\mathrm{~m}, 2 \mathrm{H}, \mathrm{H}-3^{\prime \prime \prime}\right), 7.14-7.08(\mathrm{~m}, 5 \mathrm{H}, \mathrm{Ar}), 6.92(\mathrm{t}$, $\left.J=8.79 \mathrm{~Hz}, 2 \mathrm{H}, \mathrm{H}-2^{\prime \prime \prime}\right), 5.17(\mathrm{dd}, J=9.52,6.59 \mathrm{~Hz}$, 1H, H-2'), 3.54-3.40 (m, 8H, H-1'"', $\mathrm{H}-3^{\prime}, \mathrm{H}-2^{\prime \prime}, \mathrm{H}-6^{\prime \prime}$ ), 2.60-2.20 (m, 4H, H-3", H-5") ppm; ${ }^{13} \mathrm{C}$ NMR (100 $\left.\mathrm{MHz}, \mathrm{CDCl}_{3}\right): \delta 167.62(\mathrm{C}=\mathrm{O}), 166.81(\mathrm{C}=\mathrm{O}), 162.42$ $\left(\mathrm{d},{ }^{1} J_{C-F}=251.12 \mathrm{~Hz}\right), 134.22,131.31,129.11$, $128.56,126.91,123.48,115.42\left(\mathrm{~d},{ }^{2} J_{C-F}=20.13 \mathrm{~Hz}\right)$, 61.46, 52.38, 52.21, 35.07, 29.65 ppm; HRMS m/z calculated $[\mathrm{M}]^{+}$for $\mathrm{C}_{28} \mathrm{H}_{26} \mathrm{FN}_{3} \mathrm{O}_{3}^{+}$471.1958; found 471.1969 .

2.1b5 2-((2S,3S)-1-(4-(4-fluorobenzyl)piperazin-1-yl)3-methyl-1-oxopentan-2-yl)isoindoline-1,3-dione $(\mathbf{3 h})$ : The title compound was obtained as white solid having yield: $69 \%$; M.p.: $111-113^{\circ} \mathrm{C} ;[\alpha]_{\mathrm{D}}{ }^{25}-17.3(c=0.2$ in ethylacetate); FTIR (KBr) $v_{\max }\left(\mathrm{cm}^{-1}\right) 2929,2870$, $1716(\mathrm{C}=\mathrm{O}$, imide), 1668 ( $\mathrm{C}=\mathrm{O}$, amide), 1590, 1471, 1110, $721 \mathrm{ppm} ;{ }^{1} \mathrm{H}$ NMR $\left(400 \mathrm{MHz}, \mathrm{CDCl}_{3}\right) \delta 7.82-$ 7.80 (m, 2H, H-4, H-7), 7.72-7.69 (m, 2H, H-5, H-6), 7.20-7.17 (m, 2H, H-3"') 6.99 (m, 2H, H-4"') 4.72 (d, $\left.J=10.68 \mathrm{~Hz}, 1 \mathrm{H}, \mathrm{H}-2^{\prime}\right), 3.62-3.52\left(\mathrm{~m}, 4 \mathrm{H}, \mathrm{H}-2^{\prime \prime}\right.$, H-6"), 3.38 (s, 2H, H-1"'''), 2.99-2.88 (m, 1H, H-3'), 2.37-2.25 (m, 4H, H-3", H-5") $1.35-1.39$ (m, $1 \mathrm{H}$, H-3') $1.04-1.00$ (m, 1H, ), $0.96(\mathrm{~d}, J=6.87 \mathrm{~Hz}, 3 \mathrm{H}$, $\left.\mathrm{H}-6^{\prime}\right), 0.83$ (t, $\left.J=7.33 \mathrm{~Hz}, 3 \mathrm{H}, \mathrm{H}-5^{\prime}\right) \mathrm{ppm} ;{ }^{13} \mathrm{C} \mathrm{NMR}$ $\left(100 \mathrm{MHz}, \mathrm{CDCl}_{3}\right) \delta 167.83(\mathrm{C}=\mathrm{O}), 166.88(\mathrm{C}=\mathrm{O})$, $162.02\left(\mathrm{~d},{ }^{1} J_{C-F}=244.41 \mathrm{~Hz}\right), 134.19,133.22$, 131.39, $130.46\left(\mathrm{~d},{ }^{3} J_{C-F}=7.67 \mathrm{~Hz}\right), 123.49,115.07$ $\left(\mathrm{d},{ }^{2} J_{C-F}=21.09 \mathrm{~Hz}\right), 61.84,54.90,52.67,45.74$, $42.26,33.09,25.28,16.50,10.60 \mathrm{ppm}$. HRMS $\mathrm{m} / \mathrm{z}$ calculated $[\mathrm{M}]^{+}$for $\mathrm{C}_{25} \mathrm{H}_{28} \mathrm{FN}_{3} \mathrm{O}_{3}^{+}$437.2115; found 437.2116.

$2.1 \mathrm{b6}$ (S)-2-(1-oxo-3-phenyl-1-(4-(4-(trifluoromethyl) benzyl) piperazin-1-yl)propan-2-yl) isoindoline-1,3-dione (3j): The title compound was obtained as white solid having yield $72 \%$; M.p.: $112-113^{\circ} \mathrm{C} ;[\alpha]_{\mathrm{D}}{ }^{26}-141.3$ $\left(c=0.2\right.$ in ethylacetate); FTIR $(\mathrm{KBr}) v_{\max }\left(\mathrm{cm}^{-1}\right)=$ 3060, 2928, 1712 ( $\mathrm{C}=\mathrm{O}$, imide), $1686(\mathrm{C}=\mathrm{O}$, amide), 1385, 1329, 1126, 720. ${ }^{1} \mathrm{H}$ NMR (400 $\mathrm{MHz}, \mathrm{CDCl}_{3}$ ) $\delta$ 7.76-7.73 (m, 2H, H-4, H-7), 7.68-7.66 (m, 2H, H$5, \mathrm{H}-6), 7.54\left(\mathrm{~d}, J=7.32 \mathrm{~Hz}, 2 \mathrm{H}, \mathrm{H}-3^{\prime \prime \prime}\right), 7.42-$ $7.48\left(\mathrm{~m}, 2 \mathrm{H}, \mathrm{H}-2^{\prime \prime \prime}\right), 7.16-7.12(\mathrm{~m}, 5 \mathrm{H}, \mathrm{Ar}), 5.22(\mathrm{dd}$, $\left.J=5.86,9.52 \mathrm{~Hz}, 1 \mathrm{H}, \mathrm{H}-2^{\prime}\right), 3.59-3.44(\mathrm{~m}, 8 \mathrm{H}$, H-1'"', H-3', H-2", H-6"), 2.43 (m, 4H, H-3", H-5") ppm; ${ }^{13} \mathrm{C}$ NMR $\left(100 \mathrm{MHz}, \mathrm{CDCl}_{3}\right) \delta 167.61(\mathrm{C}=\mathrm{O})$, $166.80(\mathrm{C}=\mathrm{O}), 136.86,134.20,131.29,129.09,128.55$, 126.91, 125.44, 123.47, 61.69, 52.51, 35.07, 31.87, $29.64,22.6,14.07 \mathrm{ppm}$. HRMS $\mathrm{m} / z$ calculated $[\mathrm{M}]^{+}$for $\mathrm{C}_{29} \mathrm{H}_{26} \mathrm{~F}_{3} \mathrm{~N}_{3} \mathrm{O}_{3}^{+}$521.1926; found 521.1926.

$2.1 \mathrm{~b} 7$ (S)-2-(3-methyl-1-oxo-1-(4-(4-(trifluoromethyl) benzyl) piperazin-1-yl)butan-2-yl)isoindoline-1,3-dione (3k): The title compound was obtained as white solid having yield $63 \%$; M.p.: $102-105^{\circ} \mathrm{C} ;[\alpha]_{\mathrm{D}}{ }^{25}-78.0(c=$ 0.2 in ethylacetate). FTIR $(\mathrm{KBr}) v_{\max }\left(\mathrm{cm}^{-1}\right) 2964$, 2925, 1715 ( $\mathrm{C}=\mathrm{O}$, imide), 1662 ( $\mathrm{C}=\mathrm{O}$, amide), 1467, 1383, 1326, 1126, 720. ${ }^{1} \mathrm{H}$ NMR $\left(400 \mathrm{MHz}, \mathrm{CDCl}_{3}\right)$ $\delta$ 7.83-7.80 (m, 2H, H-4, H-7), 7.74-7.69 (m, 2H, H6, H-6), $7.51\left(\mathrm{~d}, J=8.05 \mathrm{~Hz}, 2 \mathrm{H}, \mathrm{H}-3^{\prime \prime \prime}\right), 7.36(\mathrm{~d}$, $\left.J=8.05 \mathrm{~Hz}, 2 \mathrm{H}, \mathrm{H}-2^{\prime \prime \prime}\right), 4.61(\mathrm{~d}, J=10.25 \mathrm{~Hz}$, $\left.1 \mathrm{H}, \mathrm{H}-2^{\prime}\right), 3.65-3.46$ (m, 4H, H-2", H-6"), 3.47 (s, 2H, H-1'"') $)$ 3.09-3.04 (m, 1H, H-3'), 2.37-2.21 (m, 4H, $\left.\mathrm{H}-3^{\prime \prime} . \mathrm{H}-5^{\prime \prime}\right), 1.02$ (d, $\left.J=6.59 \mathrm{~Hz}, 3 \mathrm{H}, \mathrm{H}-4^{\prime}\right), 0.86$ $\left(\mathrm{d}, J=6.59 \mathrm{~Hz}, 3 \mathrm{H}, \mathrm{H}-4^{\prime}\right) \mathrm{ppm} .{ }^{13} \mathrm{C} \mathrm{NMR}(100$ $\left.\mathrm{MHz}, \mathrm{CDCl}_{3}\right) \delta 167.74(\mathrm{C}=\mathrm{O}), 166.64(\mathrm{C}=\mathrm{O}), 134.28$, 131.33, 129.21, 125.27, 123.55, 65.83, 61.99, 61.38, 56.16, 53.05, 52.74, 45.45, 42.13, 30.11, 27.55, 20.55, $19.13,15.25,14.07 \mathrm{ppm}$. HRMS $\mathrm{m} / \mathrm{z}$ calculated $[\mathrm{M}]^{+}$ for $\mathrm{C}_{25} \mathrm{H}_{26} \mathrm{~F}_{3} \mathrm{~N}_{3} \mathrm{O}_{3}^{+}$473.1926; found 473.1944.

2.1b8 2-((2S,3S)-3-methyl-1-oxo-1-(4-(4-(trifluoromethyl) benzyl)piperazin-1-yl)pentan-2-yl)isoindoline-1,3-dione (3l): The title compound was obtained as white solid having yield 59\%; M.p.: $116-118^{\circ} \mathrm{C} ;[\alpha]_{\mathrm{D}}{ }^{25}-9.37$ $\left(c=0.2\right.$ in ethylacetate); FTIR $(\mathrm{KBr}) v_{\max }\left(\mathrm{cm}^{-1}\right)=$ 2966, 2928, $1718(\mathrm{C}=\mathrm{O}$, imide $), 1638(\mathrm{C}=\mathrm{O}$, amide), 1458, 1327, 1123, 721; ${ }^{1} \mathrm{H}$ NMR $\left(400 \mathrm{MHz}, \mathrm{CDCl}_{3}\right) \delta$ 7.82-7.80 (m, 2H, H-4, H-7), 7.72-7.70 (m, 2H), 7.51 $\left(\mathrm{m}, 2 \mathrm{H}, \mathrm{H}-3^{\prime \prime \prime}\right), 7.37\left(\mathrm{~m}, 2 \mathrm{H}, \mathrm{H}-2^{\prime \prime \prime}\right), 4.73(\mathrm{~d}, J=$ $\left.10.98 \mathrm{~Hz}, 1 \mathrm{H}, \mathrm{H}-2^{\prime}\right), 3.64-3.55$ (m, 2H, H-2", H-6"),

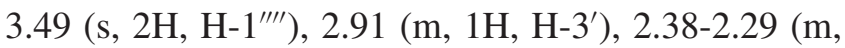


$\left.4 \mathrm{H}, \mathrm{H}-3^{\prime \prime}, \mathrm{H}-5^{\prime \prime}\right), 1.39-1.34$ (m, 1H, H-4'), 1.07-1.00 $\left(\mathrm{m}, 1 \mathrm{H}, \mathrm{H}-4^{\prime}\right), 0.97\left(\mathrm{~d}, J=6.59 \mathrm{~Hz}, 3 \mathrm{H}, \mathrm{H}-6^{\prime}\right), 0.84$ (dd, $\left.J=7.32,13.91 \mathrm{~Hz}, 3 \mathrm{H}, \mathrm{H}-5^{\prime}\right) \mathrm{ppm} ;{ }^{13} \mathrm{C} \mathrm{NMR}$ $\left(100 \mathrm{MHz}, \mathrm{CDCl}_{3}\right) \delta 167.82(\mathrm{C}=\mathrm{O}), 166.92(\mathrm{C}=\mathrm{O})$, $134.22,131.38,131.30,129.15,125.26,124.09$ (q, $\left.{ }^{1} J_{C-F}=272.20 \mathrm{~Hz}\right), 123.50,61.98,54.91,53.09$, $52.73,45.63,42.22,33.74,33.09,27.03,25.28,16.48$, $15.13,11.39,10.58, \mathrm{ppm} ; \mathrm{HRMS} \mathrm{m} / \mathrm{z}$ calculated $[\mathrm{M}]^{+}$ for $\mathrm{C}_{26} \mathrm{H}_{28} \mathrm{~F}_{3} \mathrm{~N}_{3} \mathrm{O}_{3}^{+}$487.2083; found 487.2060.

2.1b9 (S)-2-(1-(4-(4-(tert-butyl)benzyl)piperazin-1-yl)1-oxo-3-phenylpropan-2-yl)isoindoline-1,3-dione (3n): The title compound was obtained as white solid having yield $71 \%$; M.p.: $138-140^{\circ} \mathrm{C} ;[\alpha]_{\mathrm{D}}{ }^{27}-154.6(c=0.2$ in ethylacetate); FTIR (KBr) $v_{\max }\left(\mathrm{cm}^{-1}\right) 3060,2962$, $1714(\mathrm{C}=\mathrm{O}$, imide), 1663 ( $\mathrm{C}=\mathrm{O}$, amide), 1429, 1384, 1102, 716; ${ }^{1} \mathrm{H}$ NMR $\left(400 \mathrm{MHz}, \mathrm{CDCl}_{3}\right) \delta 7.76-7.73$ (m, 2H, H-4, H-7), 7.68-7.65 (m, 2H, H-5, H-6), 7.31 $\left(\mathrm{d}, J=8.79 \mathrm{~Hz}, 2 \mathrm{H}, \mathrm{H}-3^{\prime \prime \prime}\right), 7.20(\mathrm{~d}, J=7.32 \mathrm{~Hz}$, $\left.2 \mathrm{H}, \mathrm{H}-2^{\prime \prime \prime}\right), 7.17-7.12(\mathrm{~m}, 5 \mathrm{H}, \mathrm{Ar}-\mathrm{H}), 5.22(\mathrm{dd}, J=$ 9.52, $\left.5.86 \mathrm{~Hz}, 1 \mathrm{H}, \mathrm{H}-2^{\prime}\right), 3.63-3.42\left(\mathrm{~m}, 8 \mathrm{H}, \mathrm{H}-1^{\prime \prime \prime \prime}\right.$, H-3', H-2", H-6"), 2.43-2.30 (m, 4H), 1.28 (s, 9H, H-6"') ppm. ${ }^{13} \mathrm{C}$ NMR $\left(100 \mathrm{MHz}, \mathrm{CDCl}_{3}\right) \delta 167.61$ $(\mathrm{C}=\mathrm{O}), 166.68(\mathrm{C}=\mathrm{O}), 136.97,134.10,131.34,129.05$, 128.91, 128.49, 126.81, 125.23, 123.40, 62.19, 52.44, $35.01,34.43,31.29 \mathrm{ppm}$. HRMS $\mathrm{m} / \mathrm{z}$ calculated $[\mathrm{M}]^{+}$ for $\mathrm{C}_{32} \mathrm{H}_{35} \mathrm{~N}_{3} \mathrm{O}_{3}^{+}$509.2678; found 509.2702.

$2.1 b 10$ (S)-2-(1-(4-(4-(tert-butyl)benzyl)piperazin-1-yt)3-methyl-1-oxobutan-2-yl)isoindoline-1,3-dione (3o): The title compound was obtained as white solid having yield $68 \%$; M.p.: $135-137^{\circ} \mathrm{C} ;[\alpha]_{\mathrm{D}}{ }^{26}-79(c=0.2$ in ethylacetate); FTIR $(\mathrm{KBr}) v_{\max }\left(\mathrm{cm}^{-1}\right) 3008,2964$, 2871, 1714 ( $\mathrm{C}=\mathrm{O}$, imide), 1660 ( $\mathrm{C}=\mathrm{O}$, amide), 1468, $1382,1071,720 ;{ }^{1} \mathrm{H}$ NMR $\left(400 \mathrm{MHz}, \mathrm{CDCl}_{3}\right) \delta 7.82-$ 7.81 (m, 2H, H-4, H-7), 7.73-7.71 (m, 2H, H-5, H-6), $7.30\left(\mathrm{~d}, J=8.05 \mathrm{~Hz}, 2 \mathrm{H}, \mathrm{H}-3^{\prime \prime \prime}\right), 7.20(\mathrm{~d}, J=6.59$ $\left.\mathrm{Hz}, 2 \mathrm{H}, \mathrm{H}-2^{\prime \prime \prime}\right), 4.59$ (d, $\left.J=10.25 \mathrm{~Hz}, 1 \mathrm{H}, \mathrm{H}-2^{\prime}\right)$, 3.72-3.50 (m, 6H, H-1"'”, H-2", H-6"), 3.08-3.01 (m, $\left.1 \mathrm{H}, \mathrm{H}-3^{\prime}\right), 2.56-2.39$ (m, 4H, H-3", H-5"), 1.27 (s, 9H, H-6"') $1.01\left(\mathrm{~d}, J=6.59 \mathrm{~Hz}, 3 \mathrm{H}, \mathrm{H}-4^{\prime}\right), 0.85(\mathrm{~d}, J=$ $\left.6.59 \mathrm{~Hz}, 3 \mathrm{H}, \mathrm{H}-4^{\prime}\right) \mathrm{ppm} ;{ }^{13} \mathrm{C} \mathrm{NMR}\left(100 \mathrm{MHz}, \mathrm{CDCl}_{3}\right)$ $\delta 167.95(\mathrm{C}=\mathrm{O}), 166.64(\mathrm{C}=\mathrm{O}), 134.32,131.28$, $129.76,125.58,123.59,61.94,56.07,34.68,31.27$, 27.49, 20.53, $18.98 \mathrm{ppm}$; HRMS $\mathrm{m} / \mathrm{z}$ calculated $[\mathrm{M}]^{+}$ for $\mathrm{C}_{28} \mathrm{H}_{35} \mathrm{~N}_{3} \mathrm{O}_{3}^{+}$461.2678; found 461.2659.

2.1b11 2-((2S,3S)-1-(4-(4-(tert-butyl)benzyl)piperazin1-yl)-3-methyl-1-oxopentan-2-yl) isoindoline-1,3-dione $(3 p)$ : The title compound was obtained as white solid having yield $80 \%$; M.p.: $102-104^{\circ} \mathrm{C} ;[\alpha]_{\mathrm{D}}{ }^{27}-10.7$ $\left(c=0.2\right.$ in ethylacetate); FTIR $(\mathrm{KBr}) v_{\max }\left(\mathrm{cm}^{-1}\right)$
2963, 2875, 1715 ( $\mathrm{C}=\mathrm{O}$, imide), 1660 ( $\mathrm{C}=\mathrm{O}$, amide), 1463, 1381, 1073, 721; ${ }^{1} \mathrm{H}$ NMR (400 MHz, $\left.\mathrm{CDCl}_{3}\right) \delta$ 7.78-7.76 (m, 2H, H-4, H-7), 7.67-7.65 (m, 2H, H-5, H-6), 7.25 (d, $\left.J=8.05 \mathrm{~Hz}, 2 \mathrm{H}, \mathrm{H}-3^{\prime \prime \prime}\right), 7.13(\mathrm{~d}, J=$ $\left.8.05 \mathrm{~Hz}, 2 \mathrm{H}, \mathrm{H}-2^{\prime \prime \prime}\right), 4.68$ (d, $J=10.25 \mathrm{~Hz}, 1 \mathrm{H}, \mathrm{H}-2^{\prime}$ ), 3.61-3.45 (m, 4H, H-2", H-6"), 3.39 (s, 2H, H-1'"'), 2.90-2.78 (m, 1H, H-3'), 2.40-2.24 (m, 4H, H-3", H-5") $1.35-1.28$ (m, 1H, H-4'), 1.23 (s, 9H, H-6 $\left.6^{\prime \prime \prime}\right)$, 1.01-0.95 (m, 1H, H-4'), $0.93(\mathrm{~d}, J=6.59 \mathrm{~Hz}, 3 \mathrm{H}$, H-5'), 0.81 (dd, $\left.J=6.95,7.32 \mathrm{~Hz}, 3 \mathrm{H}, \mathrm{H}-5^{\prime}\right) \mathrm{ppm}$; ${ }^{13} \mathrm{C}$ NMR $\left(100 \mathrm{MHz}, \mathrm{CDCl}_{3}\right) \delta 167.83(\mathrm{C}=\mathrm{O}), 166.80$ $(\mathrm{C}=\mathrm{O}), 134.21,131.36,129.01,125.29,123.51,62.17$, 54.88, 52.98, 52.98, 45.43, 41.64, 34.46, 33.07, 31.30, $25.27,16.49,10.60 \mathrm{ppm}$; HRMS $\mathrm{m} / \mathrm{z}$ calculated $[\mathrm{M}]^{+}$ for $\mathrm{C}_{29} \mathrm{H}_{37} \mathrm{~N}_{3} \mathrm{O}_{3}^{+}$475.2835; found 475.2885.

2.1b12 (S)-2-(4-methyl-1-oxo-1-(4-phenethylpiperazin1-yl)pentan-2-yl)isoindoline-1,3-dione (3q): The title compound was obtained as yellow oil having yield $80 \% ;[\alpha]_{\mathrm{D}}^{27}-16.2(c=0.2$ in ethylacetate); FTIR $(\mathrm{KBr}) v_{\max }\left(\mathrm{cm}^{-1}\right)=2958,2928,1715(\mathrm{C}=\mathrm{O}$, imide $)$, 1670 (C=O, amide), 1438, 1381, 1197, 720; ${ }^{1} \mathrm{H}$ NMR $\left(400 \mathrm{MHz}, \mathrm{CDCl}_{3}\right) \delta$ 7.85-7.82 (m, 2H, H-4, H-7), 7.75-7.71 (m, 2H, H-5, H-6), 7.30-7.16 (m, 5H, H-1"'H-4"') 5.10 (dd, $\left.J=11.45,4.58 \mathrm{~Hz}, 1 \mathrm{H}, \mathrm{H}-2^{\prime}\right), 3.84-$

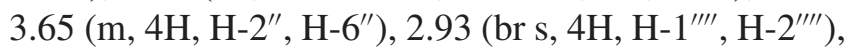
2.87-2.78 (m, 4H, H-3", H-5"), 2.60-2.55 (m, $1 \mathrm{H}$, H-3') $1.67-1.62\left(\mathrm{~m}, 1 \mathrm{H}, \mathrm{H}-3^{\prime}\right), 1.55-1.52(\mathrm{~m}, 1 \mathrm{H}$, $\left.\mathrm{H}-4^{\prime}\right), 0.95\left(\mathrm{~d}, J=1.83 \mathrm{~Hz}, 3 \mathrm{H}, \mathrm{H}-5^{\prime}\right), 0.93(\mathrm{~d}$, $\left.J=2.29 \mathrm{~Hz}, 3 \mathrm{H}, \mathrm{H}-5^{\prime}\right) \mathrm{ppm} .{ }^{13} \mathrm{C} \mathrm{NMR}(100 \mathrm{MHz}$, $\left.\mathrm{CDCl}_{3}\right) \delta 168.18(\mathrm{C}=\mathrm{O}), 167.70(\mathrm{C}=\mathrm{O}), 139.75$, 134.09, 131.65, 128.60, 128.39, 126.13, 123.41, 60.00, 53.10, 52.61, 49.96, 45.44, 42.35, 37.19, 29.64, 25.21, 23.10, $21.22 \mathrm{ppm}$; HRMS $\mathrm{m} / \mathrm{z}$ calculated $[\mathrm{M}]^{+}$for $\mathrm{C}_{26} \mathrm{H}_{31} \mathrm{~N}_{3} \mathrm{O}_{3}^{+}$433.2365; found 433.2194.

$2.1 \mathrm{~b} 13$ (S)-2-(1-oxo-1-(4-phenethylpiperazin-1-yl)-3phenylpropan-2-yl)isoindoline-1,3-dione (3r): The title compound was obtained as yellow solid having yield 72\%; M.p.: $101-103^{\circ} \mathrm{C} ;[\alpha]_{\mathrm{D}}{ }^{27}-160.7(c=0.2$ in ethylacetate); FTIR (KBr) $v_{\max }\left(\mathrm{cm}^{-1}\right) 3029,2928$, 2373, 1715 ( $\mathrm{C}=\mathrm{O}$, imide), 1675 ( $\mathrm{C}=\mathrm{O}$, amide), 1438, 1382, 1198, 720; ${ }^{1} \mathrm{H}$ NMR (400 MHz, $\left.\mathrm{CDCl}_{3}\right) \delta$ 7.80-7.76 (m, 2H, H-4, H-7), 7.73-7.70 (m, 2H, H5, H-6), 7.31-7.13 (m, 10H, Ar), $5.21(\mathrm{t}, J=8.05$ $\left.\mathrm{Hz}, 1 \mathrm{H}, \mathrm{H}-2^{\prime}\right), 3.65-3.52$ (m, 6H, H-3', H-2", H-

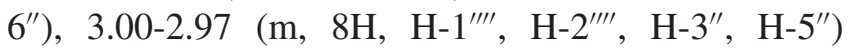
ppm; ${ }^{13} \mathrm{C}$ NMR $\left(100 \mathrm{MHz}, \mathrm{CDCl}_{3}\right) \delta 167.63(\mathrm{C}=\mathrm{O})$, $167.18(\mathrm{C}=\mathrm{O}), 136.53,135.75,134.45,131.17,129.24$, $129.02,128.73,128.56,123.37,127.20,123.62,58.44$, 52.06, 51.51, 42.70, 39.50, 35.20, 39.29 ppm, HRMS $\mathrm{m} / \mathrm{z}$ calculated $[\mathrm{M}]^{+}$for $\mathrm{C}_{29} \mathrm{H}_{29} \mathrm{~N}_{3} \mathrm{O}_{3}^{+}$467.2209; found 467.2204. 
$2.1 b 14$ (S)-2-(3-methyl-1-oxo-1-(4-phenethylpiperazin1-yl)butan-2-yl)isoindoline-1,3-dione (3s): The title compound was obtained as yellow oil having yield $61 \% ;[\alpha]_{\mathrm{D}}{ }^{27}-92(c=0.2$ in ethylacetate); FTIR $(\mathrm{KBr})$ $v_{\max }\left(\mathrm{cm}^{-1}\right) 3012,2965,2874,1715$ (C=O, imide), 1662 (C=O, amide), 1455, 1383, 1071, 721; ${ }^{1} \mathrm{H}$ NMR $\left(400 \mathrm{MHz}, \mathrm{CDCl}_{3}\right) \delta$ 7.84-7.82 (m, 2H, H-4, H-7), 7.72-7.70 (m, 2H, H-5, H-6), 7.22-7.12 (m, 5H, Ar$\mathrm{H}), 4.63\left(\mathrm{~d}, J=10.68 \mathrm{~Hz}, 1 \mathrm{H}, \mathrm{H}-2^{\prime}\right), 3.66-3.53(\mathrm{~m}$, $\left.4 \mathrm{H}, \mathrm{H}-2^{\prime \prime}, \mathrm{H}-6^{\prime \prime}\right), 3.11-3.03$ (m, 1H, H-3'), 2.75-2.71

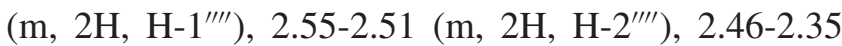
(m, 4H, H-3", H-5") 1.03 (d, $J=6.10 \mathrm{~Hz}, 3 \mathrm{H}, \mathrm{H}-$ $\left.4^{\prime}\right), 0.86\left(\mathrm{~d}, J=6.59 \mathrm{~Hz}, 3 \mathrm{H}, \mathrm{H}-4^{\prime}\right) \mathrm{ppm} ;{ }^{13} \mathrm{C} \mathrm{NMR}$ $\left(100 \mathrm{MHz}, \mathrm{CDCl}_{3}\right) \delta 167.77(\mathrm{C}=\mathrm{O}), 166.71(\mathrm{C}=\mathrm{O})$, $134.33,131.29,128.59,128.52,126.39,123.58$, 59.59, 56.14, 52.91, 52.43, 45.05, 41.47, 32.45, 27.48, 20.49, $19.14 \mathrm{ppm}$ HRMS $\mathrm{m} / \mathrm{z}$ calculated $[\mathrm{M}]^{+}$for $\mathrm{C}_{25} \mathrm{H}_{29} \mathrm{~N}_{3} \mathrm{O}_{3}^{+}$419.2209; found 419.2215.

$2.1 \mathrm{~b} 15$ 2-((2S,3S)-3-methyl-1-oxo-1-(4-phenethylpiperazin-1-yl)pentan-2-yl)isoindoline-1,3-dione (3t): The title compound was obtained as yellow oil having yield $67 \%$; $[\alpha]_{\mathrm{D}}{ }^{27}-10.7$ ( $c=0.2$ in ethylacetate); FTIR $(\mathrm{KBr}) v_{\max }\left(\mathrm{cm}^{-1}\right)=2965,2933,1715(\mathrm{C}=\mathrm{O}$, imide $)$, $1652\left(\mathrm{C}=\mathrm{O}\right.$, amide), 1456, 1382, 1073, 721; ${ }^{1} \mathrm{H}$ NMR $\left(400 \mathrm{MHz}, \mathrm{CDCl}_{3}\right) \delta$ 7.84-7.78 (m, 2H, H-4, H-7), 7.72-7.67 (m, 2H, H-5, H-6), 7.25-7.12 (m, 5H, Ar-H), $4.75\left(\mathrm{~d}, J=10.68 \mathrm{~Hz}, 1 \mathrm{H}, \mathrm{H}-2^{\prime}\right), 3.66-3.54(\mathrm{~m}, 4 \mathrm{H}$, H-2", H-6") , 2.96-2.90 (m, 1H, H-3'), 2.75-2.70 (m, $\left.2 \mathrm{H}, \mathrm{H}-1^{\prime \prime \prime \prime}\right), 2.56-2.52\left(\mathrm{~m}, 2 \mathrm{H}, \mathrm{H}-2^{\prime \prime \prime \prime}\right), 2.44-2.35$ (m, 4H, H-3", H-5"), 1.41-1.32 (m, 1H, H-4'), 1.10-1.02 $\left(\mathrm{m}, 1 \mathrm{H}, \mathrm{H}-4^{\prime}\right), 0.97\left(\mathrm{~d}, J=6.59 \mathrm{~Hz}, 3 \mathrm{H}, \mathrm{H}-6^{\prime}\right), 0.83$ $\left(\mathrm{dd}, J=6.87,13.73 \mathrm{~Hz}, 3 \mathrm{H}, \mathrm{H}-5^{\prime}\right) \mathrm{ppm} ;{ }^{13} \mathrm{C} \mathrm{NMR}$ $\left(100 \mathrm{MHz}, \mathrm{CDCl}_{3}\right) \delta 167.87(\mathrm{C}=\mathrm{O}), 167.00(\mathrm{C}=\mathrm{O})$, 134.26, 131.37, 128.60, 128.51, 126.37, 123.53, 59.58, 54.89, 53.00, 52.24, 44.86, 41.28, 33.02, 25.31, 20.87, $16.45,10.55 \mathrm{ppm}$; HRMS $\mathrm{m} / \mathrm{z}$ calculated $[\mathrm{M}]^{+}$for $\mathrm{C}_{26} \mathrm{H}_{31} \mathrm{~N}_{3} \mathrm{O}_{3}^{+}$433.2365; found 433.2365.

\subsection{Biological Experiments}

2.2a Collection of materials: Goat (Capra hircus) testes $(\mathrm{n}=10)$ were procured from the slaughter houses around Kurukshetra $\left(26^{\circ} 6^{\prime} \mathrm{N}, 76^{\circ} 5^{\prime} \mathrm{E}\right)$, India and brought to laboratory in normal saline at $4^{\circ} \mathrm{C}$. Subsequently, the testes were decapsulated, cut into smaller pieces (Approximately $1 \mathrm{~mm}^{3}$ ) and processed for testicular tissue culture in vitro.

2.2b Testicular tissue culture in vitro: The testicular tissues $\left(1 \mathrm{~mm}^{3}\right)$ were washed three times with phosphate buffer saline (PBS) and then cultured in
Dulbecco's modified Eagle's Medium (DMEM) supplemented with antibiotics (200-unit having concentration of penicillin $100 \mathrm{IU} / \mathrm{mL}$ and streptomycin $100 \mathrm{IU} / \mathrm{mL}$ ) in $\mathrm{CO}_{2}$ incubator $\left(5 \% \mathrm{CO}_{2}, 95 \%\right.$ humidity, $\left.38^{\circ} \mathrm{C}\right)$. The testicular tissues were incubated with $10 \mu \mathrm{M}$ of each tested compound in DMSO. Thereafter, the harvesting of testicular tissues was performed after $6 \mathrm{~h}$ of culture duration. The harvested testicular tissue cultures were washed with PBS and fixed in alcoholic Bouin's fixative for $24 \mathrm{~h}$. Following dehydration in series of ethanol grades, the testicular tissues were cleared in xylene and embedded in paraffin wax. The paraffin blocks were prepared and sections were cut at 5-7 $\mu \mathrm{m}$ thickness. These sections were deparaffinised in xylene, stained with haematoxylin and eosin, and then mounted in DPX. The specific sections were observed under microscope (Olympus, Japan). ${ }^{38,39}$

\section{2c Testicular germ cell isolation and treatment with}

3j: A two-step enzymatic method was used to isolate the germ cells from the goat testis with a few modifications as described previously. ${ }^{14,15}$ Briefly, the excised testis was rinsed in $10 \mathrm{~mL}$ of Hank's balanced salt solution (HBSS) and the tunica albuginea along with other visible connective tissues were removed. The seminiferous tubule mass $(4-5 \mathrm{~g})$ was transferred to $10 \mathrm{~mL}$ fresh HBSS containing $0.25 \mathrm{mg} / \mathrm{mL}$ collagenase and kept for 15 minutes at $37^{\circ} \mathrm{C}$ with constant shaking. The dispersed seminiferous tubules were allowed to sediment and washed thrice in the fresh HBSS. The supernatant was decanted each time, which largely removed contamination from the interstitial and blood cells. The isolated tubules were washed and subjected to trypsin $(1.25 \mathrm{mg} / \mathrm{mL})$ and DNase I $(50 \mu \mathrm{g} / \mathrm{mL})$ treatment for $10-15$ min with shaking. The resultant crude cell suspension was filtered through $100 \mu \mathrm{m}$ and $43 \mu \mathrm{m}$ mesh filter which removed clumped/clustered cells, washed following centrifugation at $500 \mathrm{~g}$ for $5 \mathrm{~min}$ at room temperature and re-suspended in DMEM containing $100 \mu \mathrm{g} / \mathrm{mL}$ streptomycin sulphate and $100 \mathrm{IU} / \mathrm{mL}$ penicillin. Viability of the final cell preparation was $>95 \%$ as determined by trypan blue exclusion method. The isolated testicular germ cells $\left(5 \times 10^{6}\right.$ cells $/ \mathrm{mL} /$ tube $)$ were incubated for $6 \mathrm{~h}$ at $38^{\circ} \mathrm{C}$ with or without $\mathbf{3 j}$ in DMEM. Phthalimide $\mathbf{3 j}$ exhibited substantial apoptotic induction $(\sim 68 \%)$, hence chosen for further investigation. Incubations with $\mathbf{3 j}$ were made at final concentrations of $0,2,5,10$ and $20 \mu \mathrm{M}$. The treated cells were washed in PBS and stored at $-20^{\circ} \mathrm{C}$ till further use. Approximately, $80 \%$ cells were viable in $10 \mu \mathrm{M}$ $3 \mathbf{j}$ exposed group, however the viability was $\sim 65 \%$ in $20 \mu \mathrm{M} 3 \mathbf{j}$ treated group. Therefore, $10 \mu \mathrm{M}$ was used in further studies and treatments. 
2.2d In Situ End Labelling (TUNEL Assay): Testicular germ cells were harvested from the mature goat (Capra hircus) testes and cultured in DMEM medium supplemented with antibiotics (200 unit penicillin $100 \mathrm{IU} / \mathrm{mL}$ and streptomycin $100 \mathrm{IU} / \mathrm{mL}$ ) in $\mathrm{CO}_{2}$ incubator $\left(5 \% \mathrm{CO}_{2}, 95 \%\right.$ humidity, $\left.38^{\circ} \mathrm{C}\right)$ for $6 \mathrm{~h}$ culture duration. The cells were plated at a density of $10^{5}$ cells $/ \mathrm{mL}$ and incubated with $10 \mu \mathrm{M}$ of each tested compound in DMSO. Then the cell apoptosis was assayed by TUNEL (Terminal deoxynucleotidyl-transferase d-UTP mediated nick end labelling). TUNEL was carried out as per manufacturer's (R\&D Systems, Inc., Minneapolis, MN, USA) instructions. Briefly, the testicular germ cells were smeared on poly-L-Lysine coated slides and fixed in $4 \%$ formaldehyde. Cells were treated with cytonin for 10 min followed by quenching with $\mathrm{H}_{2} \mathrm{O}_{2}$. Biotinylated nucleotides were incorporated in to 3'-OH ends of the DNA fragments by TdT, and detected by using streptavidin horseradish peroxidase (HRP). The colour was developed by diaminobenzidine (DAB) solution and counterstained with methyl green. TUNEL positive cells were examined under a microscope. ${ }^{40,41}$

2.2e Acridine orange fluorescence: Testicular germ cells were harvested from the mature goat (Capra hircus) testes and cultured in DMEM medium supplemented with antibiotics (200 unit penicillin $100 \mathrm{IU} / \mathrm{mL}$ and streptomycin $100 \mathrm{IU} / \mathrm{mL}$ ) in $\mathrm{CO}_{2}$ incubator $(5 \%$ $\mathrm{CO}_{2}, 95 \%$ humidity, $38^{\circ} \mathrm{C}$ ) for $6 \mathrm{~h}$ culture duration. The cells were plated at a density of $10^{5}$ cells $/ \mathrm{mL}$ and incubated with $10 \mu \mathrm{M}$ of each tested compound in DMSO. Then the cell apoptosis was assayed by Acridine Orange staining after $6 \mathrm{~h}$ of culture duration under fluorescence microscope (Olympus, Japan) using 500$525 \mathrm{~nm}$ filters. Normal cells were identified by their intact cell membrane and round nucleus with scanty chromatin. Cells with bright green condensed nuclei (intact or fragmented) were interpreted as apoptotic. ${ }^{38}$

\section{2f Lipid peroxidation and antioxidant enzymes} activity: Treated or untreated testicular germ cells were sonicated for $30 \mathrm{~s}$ and divided into two equal parts. One part was assayed for lipid peroxidation through the formation of thiobarbituric acid reactive substances (TBARS) in the reaction mixture as described in literature. ${ }^{42}$ The second part was centrifuged at $10000 \mathrm{~g}$ for $5 \mathrm{~min}$ and the supernatant was assayed for antioxidant enzyme activity. SOD was measured following the literature procedure. ${ }^{43}$ Catalase was estimated by the degradation of hydrogen peroxide $(6 \mathrm{mM})$ as described by Aebi. ${ }^{44}$ GST activity towards 1-chloro-2,4dinitrobenzene (CDNB) was measured by the reported method. ${ }^{45}$ Protein was estimated by Bradford assay. ${ }^{46,47}$ 2.2g Caspase 3, 8, 9 activities: The activity of caspase $3 / 8 / 9$ was assayed as per the manufacturer's protocol supplied in the caspase colorimetric assay kit (Biovision, San Diego, CA, USA). Briefly, germ cells were resuspended in cold lysis buffer and incubated for $10 \mathrm{~min}$. Cell lysates were centrifuged for $2 \mathrm{~min}$ at 10000 $g$ at $4^{\circ} \mathrm{C}$. An aliquot of supernatant $(100 \mu \mathrm{g}$ protein/ $50 \mu \mathrm{L})$ was added to $50 \mu \mathrm{L}$ of reaction buffer containing $200 \mu \mathrm{M}$ of chromogen (Ac-DEVD-pNA/Ac-IETDpNA/Ac-LEHD-pNA for caspase 3, 8, 9 respectively), kept at $37^{\circ} \mathrm{C}$ for $2 \mathrm{~h}$ and terminated by adding stop buffer. The change in the absorbance due to the release of $p$-nitroanilide ( $p$-NA) was measured at $405 \mathrm{~nm}$ using micro-titre plate reader (BioTek Inc., USA).

2.2h Western blot analysis: Primary antibodies (rabbit polyclonal) anti-Caspase 9, anti-JNK, c-Jun, PARP and (mouse monoclonal) anti-Caspase 8, anti-pJNK, antip-c-Jun, anti-p53, anti- $\beta$-actin (Santa Cruz Biotechnology, Santa Cruz, CA, USA) were utilized. Goat antirabbit/mouse-HRP conjugate secondary antibody from Santa Cruz Biotechnology was procured. Lysates were prepared and western blotting was carried out following literature method. ${ }^{15}$ Briefly, whole cell lysates were prepared in $200 \mu \mathrm{L}$ lysis buffer containing $20 \mathrm{mM}$ HEPES (pH 7.4), $2 \mathrm{mM}$ EDTA, $50 \mathrm{mM} \beta$-glycerophosphate, $1 \%$ Triton X-100, $150 \mathrm{mM} \mathrm{NaCl}, 10 \%$ Glycerol and protease inhibitor cocktail (Roche, Basel, Switzerland). $\beta$-actin was used to monitor equal loading of protein. Densitometric analysis was performed with the help of Image analysis software (Lab Works Image analysis software 4.0, UVP, Upland, CA, USA).

2.2i RNA isolation and RT-PCR analysis: Total RNA was isolated using TRI-Reagent (Ambion, TX, USA). $c$ DNA was synthesized using $2 \mu \mathrm{g}$ of the total RNA by omniscript RT kit (Qiagen, Hilden, Germany). $2 \mu \mathrm{L}$ of the RT reaction was then used for PCR using the HotStar HiFidelity DNA polymerase (Qiagen). Primers were procured from Eurofins MWG Operon (Whitefield, Bangalore, India). The PCR reactions were carried out under the following temperature profile: (1) denaturation at $95^{\circ} \mathrm{C}$ for $15 \mathrm{~min}$; (2) 28 30 cycles of $95^{\circ} \mathrm{C}$ for $30 \mathrm{sec}, 60-65^{\circ} \mathrm{C}$ for $1 \mathrm{~min}, 72^{\circ} \mathrm{C}$ for $1 \mathrm{~min}$; (3) a final extension for $10 \mathrm{~min}$ at $72^{\circ} \mathrm{C}$. The sequence, source, annealing temperature, $\mathrm{Mg}^{2+}$ concentration, PCR cycles and product size of primers are shown in Table S2 (Supporting Information). After amplification, the products were separated on $1.5 \%$ agarose and documented with the help of gel documentation system (UVP, CA, USA). $\beta$-actin was used as an internal control. The analysis of RT-PCR results was 
completed with the aid of Image analysis software (Lab Works Image analysis software 4.0, UVP, Upland, CA, USA).

\section{$2.2 \mathrm{j}$ Cell viability studies using cancer cell lines:} The viability of two cancer cell lines was evaluated using the five most promising phthalimides in terms of apoptotic activity $(\mathbf{3 b}, \mathbf{3 f}, \mathbf{3 j}, \mathbf{3} \mathbf{m} \& \mathbf{3 p})$. The doseresponse behaviour was studied and, when applicable, the $\mathrm{IC}_{50}$ value was estimated. MCF-7 cells (human breast cancer cell line) and CAL-72 cells (human bone cancer cell line) were cultured in Roswell Park Memorial Institute-1640 and Minimum Essential Media, respectively, supplemented with $10 \%$ heat-inactivated fetal bovine serum (Gibco) and 1\% antibioticantimycotic 100X solution (containing penicillin, streptomycin and amphotericin B; Gibco). Cells were grown in a humidified incubator at $37^{\circ} \mathrm{C}$ and $5 \% \mathrm{CO}_{2}$. The subconfluent cells were harvested using a trypsin solution (Sigma-Aldrich).

To determine the metabolic activity of both cancer cell lines, cells were plated in 96-well plates, at a different density for each cell line: 10000 cells (MCF-7) and 5000 cells (CAL-72) per well. Cells were seeded diluted in $100 \mu \mathrm{L}$ of culture medium and were allowed to adhere overnight. Then, after media removal, they were treated with the compounds under testing at different concentrations: $100 \mu \mathrm{M}, 80 \mu \mathrm{M}, 60 \mu \mathrm{M}, 40 \mu \mathrm{M}$, $20 \mu \mathrm{M}, 10 \mu \mathrm{M}, 5 \mu \mathrm{M}, 2.5 \mu \mathrm{M}$ and $1 \mu \mathrm{M}$ (final concentrations in the wells). For this, a mother solution of each compound was prepared in DMSO and serial dilutions with DMSO were made to attain the desired concentrations. At the end, $10 \mu \mathrm{L}$ of the different solutions were added to each well together with $990 \mu \mathrm{L}$ of cell culture medium. The respective controls were performed with the adequate $1 \%(\mathrm{v} / \mathrm{v})$ of DMSO.

The effect of the compounds was evaluated by the resazurin reduction assay. After cell incubation with compounds for $48 \mathrm{~h}$, culture medium was removed replaced with fresh medium containing resazurin at a concentration of $0.1 \mathrm{mg} / \mathrm{mL}$ (Sigma-Aldrich) for $4 \mathrm{~h}$. Afterwards, aliquots of the cell supernatant were transferred to 96-well opaque plates and the resorufin fluorescence $\left(\lambda_{\mathrm{ex}}=530 \mathrm{~nm}, \lambda_{\mathrm{em}}=590 \mathrm{~nm}\right)$ was measured using a microplate reader (Victor3 1420, PerkinElmer).

2.2k Statistical Analysis: Each Figure (for western blotting and RT-PCR) is a representative of three independent experiments with similar results. The error bars represent standard deviations (SD) of three experiments done in triplicates. Statistical analysis was performed using Student's t test and one-way ANOVA followed by Tukey's test using SPSS-15. The results were considered statistically significant at $\mathrm{p}<0.05$.

\subsection{Molecular Docking methodology}

In silico docking of $\mathbf{3 j}$ into the active sites of caspase proteins was performed using the Glide (Schrödinger suite version 9.3) software. ${ }^{48}$ Initially, the ligand bound complex crystal structures of seven human caspases were obtained from protein data bank (RCSB-PDB). ${ }^{49}$ The ligand and water molecules were removed, and hydrogen atoms were added to the crystal structure followed by all-atom charges. Atom types were assigned. Protein preparation wizard of Glide was used for energy minimization and refinement of the structure. The optimized target proteins were taken for docking studies. The compound 3j was drawn in 2D sketcher. ${ }^{50}$ LigPrep protocol ${ }^{51}$ was used for further minimization and to ensure the correct protonated state for the ligand. Before docking, experimental ligand binding sites from crystal structure was obtained to define an active site in each caspases. The ligand (3j) was docked into the active sites of each caspase protein using the "extraprecision" (XP) mode of the Glide cross-docking program. Multiple conformers of the ligand $(\mathbf{3 j}$ ) were docked eventually against each rigid receptor (caspases) followed by a flexible docking protocol. ${ }^{52}$ A binding free energy $\left(\Delta \mathrm{G}_{\text {bind }}\right)$ for each docked pose was further estimated using Prime MM-GBSA method. ${ }^{53}$ The complex that had the lowest glide score was refined using $\Delta \mathrm{G}$ bind score.

\section{Results and Discussion}

\subsection{Synthesis and characterization of the different phthalimides}

To achieve the designed compounds, the starting materials $N$-phthaloyl-L-amino acids (1a-d) were synthesized following the literature procedure ${ }^{54} \mathrm{~N}$-phthaloylL-amino acids were coupled with arylpiperazines (2a-e) in the presence of 1-ethyl-3-(3-dimethylaminopropyl) carbodiimide hydrochloride (EDC. $\mathrm{HCl})$ and hydroxylbenzotriazole (HOBt) as a coupling reagent and racemization inhibitor, respectively (scheme 1). Triethylamine (TEA) was employed as a base in the reaction. The composition of new phthalimides was confirmed by spectroscopic techniques i.e., NMR $\left({ }^{1} \mathrm{H}\right.$ and ${ }^{13} \mathrm{C}$ ), IR and HRMS. In NMR spectra, the chemical shifts of various protons and carbons were assigned using DEPT-45, 90, 135 and HETCOR experiments. The coupling between the protons was assigned with 


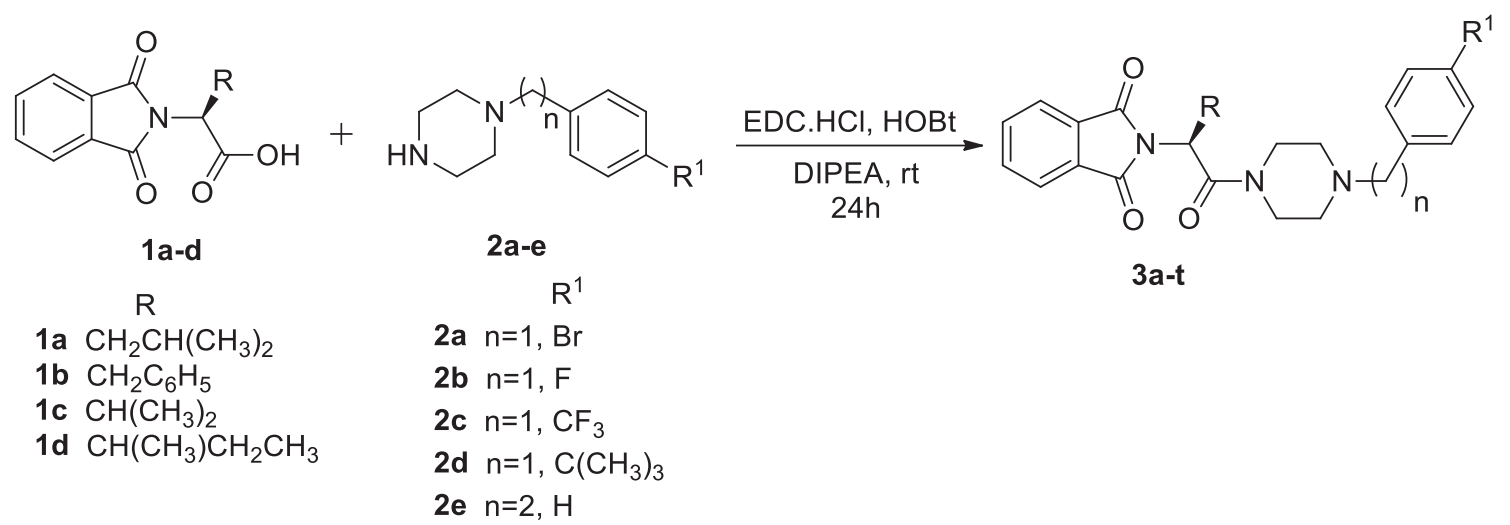

Scheme 1. Synthesis of piperazine based phthalimides.

the aid of COSY experiment. The IR spectra of phthalimides (3a-t) exhibited two characteristic stretching bands $\left(\sim 1714 \mathrm{~cm}^{-1}\right.$ and $\left.\sim 1650 \mathrm{~cm}^{-1}\right)$ attributed to the isoindoline ring and amide carbonyls, respectively.

\subsection{Biological experiments}

3.2a Apoptotic activity, morphological changes induced by various arylpiperazine based phthalimides and their structure-activity relationship: All the listed phthalimides (3a-t) were screened for in vitro apoptotic assessment against testicular germ cells of goat (Capra hircus) using histological and molecular (TUNEL assay and fluorescence assay) techniques. The cell degenerating efficiency of new phthalimides is summarized in Table 1.

Five phthalimides (3b, 3f, 3j, 3m \& 3p) were identified as potential apoptotic inducers. In the control group, the testicular tissue sections were stained with hematoxylin and eosin, which revealed the normal arrangement of spermatogonia, spermatocytes, spermatids and sperms as shown in Figure 2A. In the experimental group, the testicular tissue sections were treated with 3 of the most promising phthalimides $(\mathbf{3 b}, \mathbf{3 j}$ \& $\mathbf{3 m})$ at the concentration of $10 \mu \mathrm{M}$. This resulted in atretic changes viz., hyalinization, margination of chromatin material, pinching off of the nuclear material, pyknotic nuclei, crescent-shaped nuclei, chromolysis,

Table 1. The percentage of apoptotic cell death induced by phthalimides against testicular germ cells (model: Capra hircus). The testicular tissues were incubated with phthalimides $\left(10 \mu \mathrm{M}\right.$ in DMSO) for $6 \mathrm{~h}$ at $38^{\circ} \mathrm{C}$.

\begin{tabular}{|c|c|c|c|c|c|}
\hline Entry & $\mathrm{R}$ & $\mathrm{n}$ & $\mathrm{R}_{1}$ & $\%$ Yield & Atretic germ cells (\%) \\
\hline $\mathbf{3 a}$ & $\mathrm{CH}_{2} \mathrm{CH}\left(\mathrm{CH}_{3}\right)_{2}$ & 1 & $\mathrm{Br}$ & 82 & $51.33 \pm 5.03$ \\
\hline $3 \mathbf{b}$ & $\mathrm{CH}_{2} \mathrm{C}_{6} \mathrm{H}_{5}$ & 1 & $\mathrm{Br}$ & 72 & $64.67 \pm 5.13$ \\
\hline $3 c$ & $\mathrm{CH}\left(\mathrm{CH}_{3}\right)_{2}$ & 1 & $\mathrm{Br}$ & 62 & $46.33 \pm 4.50$ \\
\hline 3d & $\mathrm{CH}_{3} \mathrm{CHCH}_{2} \mathrm{CH}_{3}$ & 1 & $\mathrm{Br}$ & 69 & $48.67 \pm 4.72$ \\
\hline $3 \mathbf{e}$ & $\mathrm{CH}_{2} \mathrm{CH}\left(\mathrm{CH}_{3}\right)_{2}$ & 1 & $\mathrm{~F}$ & 68 & $43.33 \pm 4.04$ \\
\hline 3f & $\mathrm{CH}_{2} \mathrm{C}_{6} \mathrm{H}_{5}$ & 1 & $\mathrm{~F}$ & 65 & $64.00 \pm 3.00$ \\
\hline $3 g$ & $\mathrm{CH}\left(\mathrm{CH}_{3}\right)_{2}$ & 1 & $\mathrm{~F}$ & 85 & $39.00 \pm 5.00$ \\
\hline 3h & $\mathrm{CH}_{3} \mathrm{CHCH}_{2} \mathrm{CH}_{3}$ & 1 & $\mathrm{~F}$ & 69 & $45.33 \pm 3.21$ \\
\hline $3 \mathbf{i}$ & $\mathrm{CH}_{2} \mathrm{CH}\left(\mathrm{CH}_{3}\right)_{2}$ & 1 & $\mathrm{CF}_{3}$ & 71 & $53.33 \pm 4.04$ \\
\hline $3 \mathbf{j}$ & $\mathrm{CH}_{2} \mathrm{C}_{6} \mathrm{H}_{5}$ & 1 & $\mathrm{CF}_{3}$ & 72 & $68.67 \pm 5.50$ \\
\hline $3 \mathbf{k}$ & $\mathrm{CH}\left(\mathrm{CH}_{3}\right)_{2}$ & 1 & $\mathrm{CF}_{3}$ & 63 & $48.00 \pm 4.58$ \\
\hline 31 & $\mathrm{CH}_{3} \mathrm{CHCH}_{2} \mathrm{CH}_{3}$ & 1 & $\mathrm{CF}_{3}$ & 59 & $43.00 \pm 5.56$ \\
\hline $3 \mathrm{~m}$ & $\mathrm{CH}_{2} \mathrm{CH}\left(\mathrm{CH}_{3}\right)_{2}$ & 1 & $\mathrm{C}\left(\mathrm{CH}_{3}\right)_{3}$ & 75 & $66.67 \pm 4.50$ \\
\hline $3 \mathbf{n}$ & $\mathrm{CH}_{2} \mathrm{C}_{6} \mathrm{H}_{5}$ & 1 & $\mathrm{C}\left(\mathrm{CH}_{3}\right)_{3}$ & 71 & $59.67 \pm 3.05$ \\
\hline 30 & $\mathrm{CH}\left(\mathrm{CH}_{3}\right)_{2}$ & 1 & $\mathrm{C}\left(\mathrm{CH}_{3}\right)_{3}$ & 68 & $42.00 \pm 5.13$ \\
\hline $3 \mathbf{p}$ & $\mathrm{CH}_{3} \mathrm{CHCH}_{2} \mathrm{CH}_{3}$ & 1 & $\mathrm{C}\left(\mathrm{CH}_{3}\right)_{3}$ & 80 & $62.67 \pm 4.04$ \\
\hline $\mathbf{3 q}$ & $\mathrm{CH}_{2} \mathrm{CH}\left(\mathrm{CH}_{3}\right)_{2}$ & 2 & $\mathrm{H}$ & 80 & $48.67 \pm 3.51$ \\
\hline $3 \mathbf{r}$ & $\mathrm{CH}_{2} \mathrm{C}_{6} \mathrm{H}_{5}$ & 2 & $\mathrm{H}$ & 72 & $61.33 \pm 4.50$ \\
\hline $3 s$ & $\mathrm{CH}\left(\mathrm{CH}_{3}\right)_{2}$ & 2 & $\mathrm{H}$ & 61 & $41.33 \pm 5.50$ \\
\hline $3 t$ & $\mathrm{CH}_{3} \mathrm{CHCH}_{2} \mathrm{CH}_{3}$ & 2 & $\mathrm{H}$ & 67 & $45.67 \pm 6.11$ \\
\hline
\end{tabular}



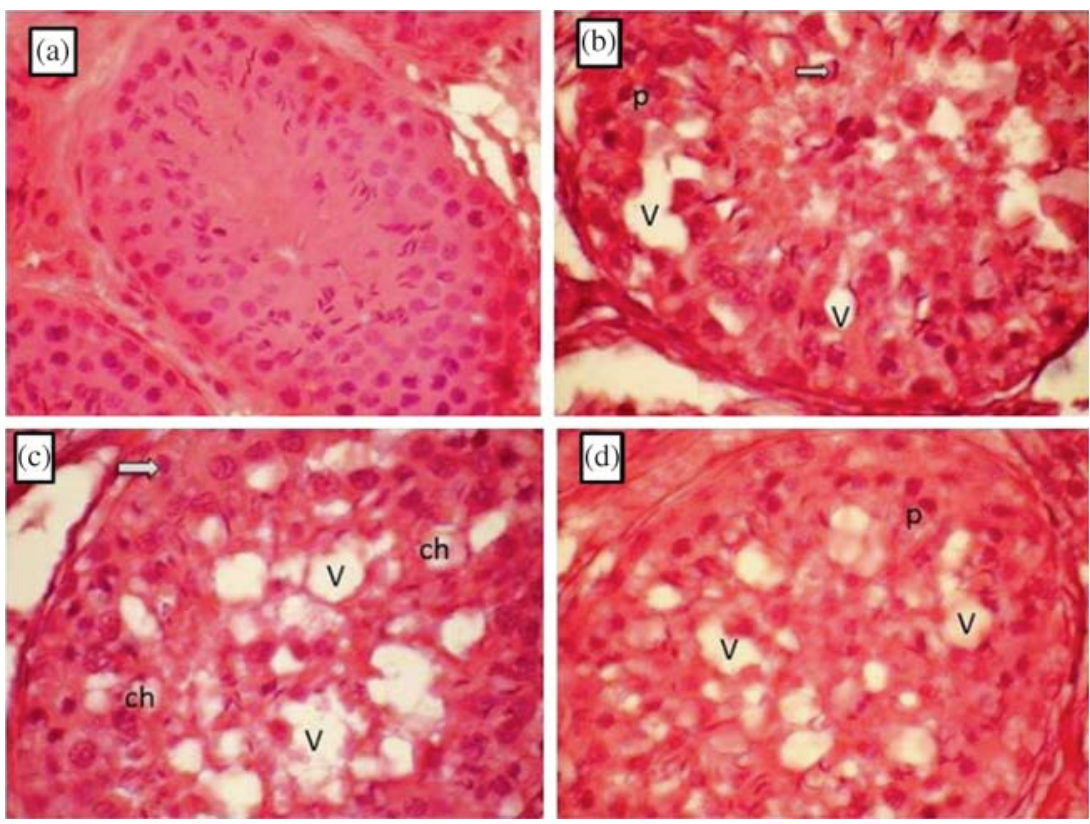

Figure 2. A) Photomicrograph of testicular tissue showing the normal arrangement of spermatogonia, spermatocytes, spermatids and sperms in the control group; B) Testicular tissue treated with phthalimide $\mathbf{3 b}$ showing dark pyknotic nuclei (p) chromatin margination (arrow) and vacuolization (v); C) Testicular tissues treated with $\mathbf{3 j}$ showing the degenerating changes such as chromolysis (ch) nuclear condensation, crescent-shaped nuclei (arrow) and increased vacuolization (v); D) Testicular tissue treated with $\mathbf{3 m}$ showing a large number of atretic changes in the germ cells such as pyknotic nuclei (p) and vacuolization (v) H \&E (×1000).

vacuolization and fragmentation of nuclei, etc., as shown in Figure 2B-D.

In 3' end labelling, the cells with single small densely stained nucleus were frequently observed (Figure 3B). The appearance of cells with fragmented and marginated chromatin material in the nucleus was noticed as shown in Figure 3C. Also, the cells with multiple small dark brown nuclear fragments were also frequently seen (Figure 3D). The fluorescent microscopy of testicular germ cells (control group) revealed pinkish normal germ cells with their intact cell membranes and round nuclei (Figure 4A). However, the testicular germ cells upon treatment with phthalimides $(\mathbf{3 b}, \mathbf{3} \mathbf{j}$ and $\mathbf{3 m})$ showed apoptotic effect with bright green condensed nuclei (Figure 4B-D).

Based on the results of apoptotic activity of phthalimides, the structure-activity relationship was described. The isoindoline ring was kept common, whereas substituents on C-2 and fourth position of piperazine were varied. From the apoptotic activity summarized in Table 1, it is evident that most of the phthalimides possessing benzyl ring on $\mathrm{C}-2$ position proved to be of higher potential than those having isobutyl, secbutyl, and isopropyl substituents. This advocates the hydrophobic binding pocket around C-2 position. All the compounds possessing isopropyl ring at $\mathrm{C}-2$ position showed the least apoptotic activity. The substitution of trifluoromethyl group (3j) with a $t$-butyl group (3n) retaining benzyl group at the C-2 position, decreases the potency, suggesting a space limited but hydrophilic pocket around the fourth position of piperazine ring. Substitution of fluorine (3j) with bromine (3b) does not make any significant difference. The potency in the context of positional isomers was also quite interesting. Phthalimide $\mathbf{3 m}$ is a positional isomer of $\mathbf{3 p}$ and showed an almost similar rate of activity i.e. percentage of atretic cells $\sim 66$ and $\sim 62 \%$, respectively. Similarly, $\mathbf{3} \mathbf{a}$ and $\mathbf{3 d}$ are the positional isomers and can degenerate $\sim 51$ and $\sim 49 \%$ testicular germ cells, respectively. The apoptotic efficacy in context to the substituents on $\mathrm{C}-2$ position attains the order viz. benzyl $>$ isobutyl $>$ sec-butyl $>$ isopropyl. Among all phthalimides, $\mathbf{3 j}$ possessing benzyl substituent at the C-2 position and the 4-trifluorobenzyl substituent at the fourth position of piperazine was identified as the most potent apoptotic inducer and may be a strong contender for the future development of cancer chemotherapy. 

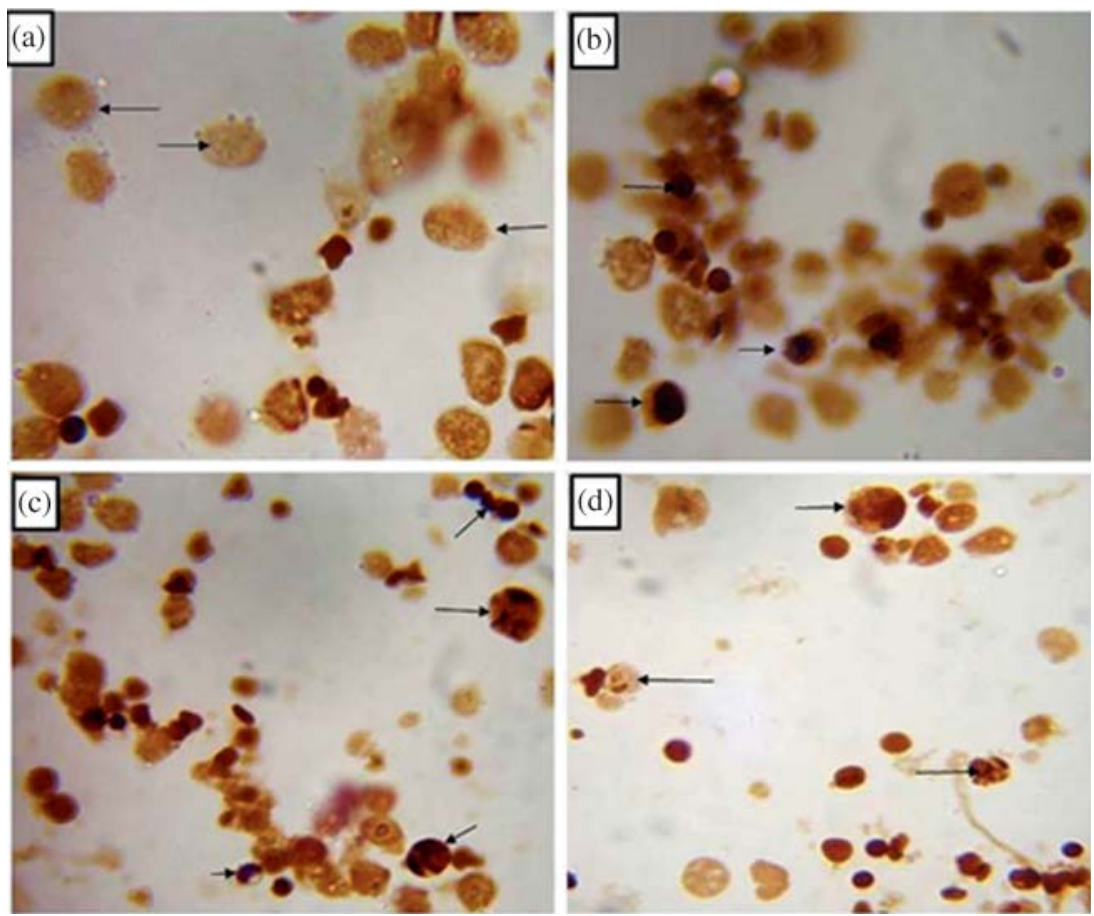

Figure 3. A) Photomicrograph of TUNEL stained testicular germ cells showing light stained normal germ cells with their intact cell membrane in control group (arrow) $\times 1000$; B) TUNEL stained apoptotic testicular germ cells treated with Compound $\mathbf{3} \mathbf{j}$ showing single small densely stained nucleus having pyknotic appearance (arrow) $\times 1000$; C) stained testicular germ cells treated with compound $\mathbf{3 m}$ showing apoptotic germ cell with nuclei containing the condensed and marginated chromatin (arrow) $\times 1000$; D) TUNEL stained testicular germ cells with $\mathbf{3 b}$ showing cells with multiple small nuclear fragments and crescent shaped nucleus (arrow) $\times 1000$.

3.2b Cellular oxidative stress study: The testicular germ cells were treated with the most potent phthalimide (3j), homogenised and assayed for cellular oxidative stress by estimation of lipid peroxidation level and Catalase, Glutathione- $S$-transferase (GST), ${ }^{55}$ and Superoxide dismutase (SOD) activities. The treatment of germ cells with most active phthalimide $\mathbf{3 j}$ resulted in an immediate rise in the lipid peroxidation level. The effect became pronounced and significant $(\mathrm{p}<0.01)$ in the cells treated with the treatment with $10-20 \mu \mathrm{M}$ of $3 \mathbf{j}$ (Figure 5A). The antioxidant enzymes viz, Catalase, GST, and SOD isolated from treated cells $(2 \mu \mathrm{M}$ to $20 \mu \mathrm{M}$ of $\mathbf{3 j}$ ) showed significantly $(\mathrm{p}<0.01)$ decline in their activities (Figure 5B, C, D). The results obtained from 10 and $20 \mu \mathrm{M}$ concentration of $\mathbf{3 j}$ were comparable (not significantly different) among them. This study suggests that $10 \mu \mathrm{M}$ dose of $\mathbf{3 j}$ is enough to induce redox imbalance in the germ cells.

3.2c Activation of JNK and p53 observed in apoptotic germ cells: The treatment of phthalimide $\mathbf{3} \mathbf{j}$ to germ cells not only induces the activation of the intrinsic pathway but also other pathways of apoptotic induction like JNK and p53. Western blot analysis of mitogenactivated protein (MAP) kinases, c-jun-N-terminal kinase (JNK), its downstream target c-Jun (which is a transcription factor, act as a pro-apoptotic factor) and their phosphorylated forms showed a rise in the expression/phosphorylation as compared to the untreated controls (Figure 6A-C). This advocated the crucial role of JNK and c-Jun in the apoptotic induction of $\mathbf{3 j}$. The expression level was observed optimal when cells were treated with 10-20 $\mu \mathrm{M}$ concentration of phthalimide $\mathbf{3 j}$. Tumour suppressor, p53 protein expression was seen as upregulated in all treatment groups irrespective of the treatment dose (Figure 6A-C). These results revealed a significant role of JNK and p53 in apoptotic induction.

\section{2d Molecular mechanism of germ cell apoptosis:}

Phthalimide induces apoptosis via intrinsic pathway: The study of the activation of caspases leading to programmed cell death could provide mechanistic information regarding the available anticancer drugs. A number of caspases are involved in the process of apoptosis as mentioned earlier. However, caspase 9 which is an important mediator of the intrinsic or mitochondrial 

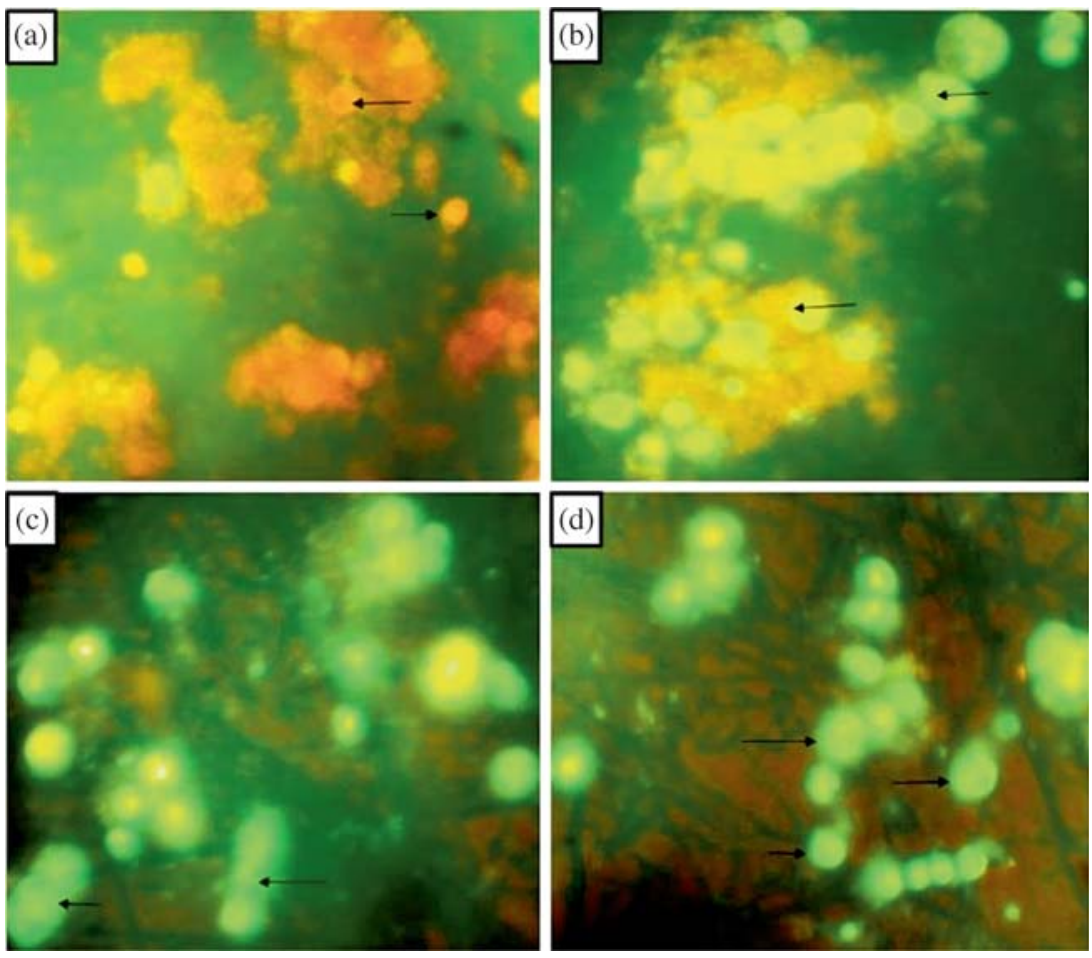

Figure 4. A) Fluorescent photograph of testicular germ cells showing pinkish normal germ cells with intact cell membrane and round nuclei in control group (arrow) $\times 400$; B) Testicular germ cells supplemented with $\mathbf{3 b}$ showing increase in number of apoptotic germ cells (arrow) $\times 400$; C) Fluorescent photograph of testicular germ cells supplemented with $\mathbf{3} \mathbf{j}$ showing apoptotic germ cell with a comet-like appearance (arrow) $\times 400$; D) Testicular germ cells supplemented with $\mathbf{3 m}$ showing a large number of apoptotic germ cells with bright green condensed nuclei $\times 400$.
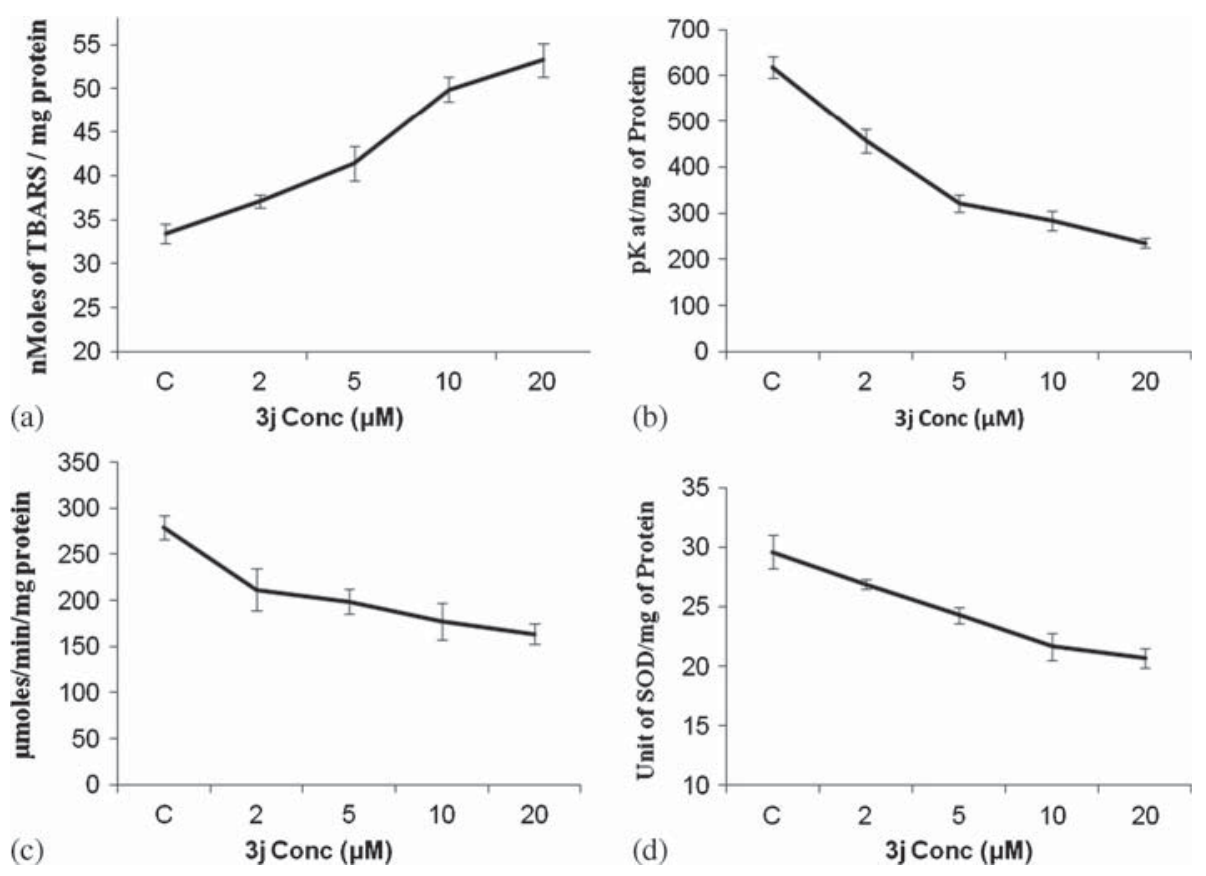

Figure 5. Plate showing the redox imbalance in testicular germ cells upon the treatment of $2-20 \mu \mathrm{M}$ of $3 \mathrm{j}$. A) Lipid peroxidation level by estimating TBRAS levels; B) catalase activity; C) Glutathione- $S$-Transferase activity; D) Superoxide Dismutase level. 


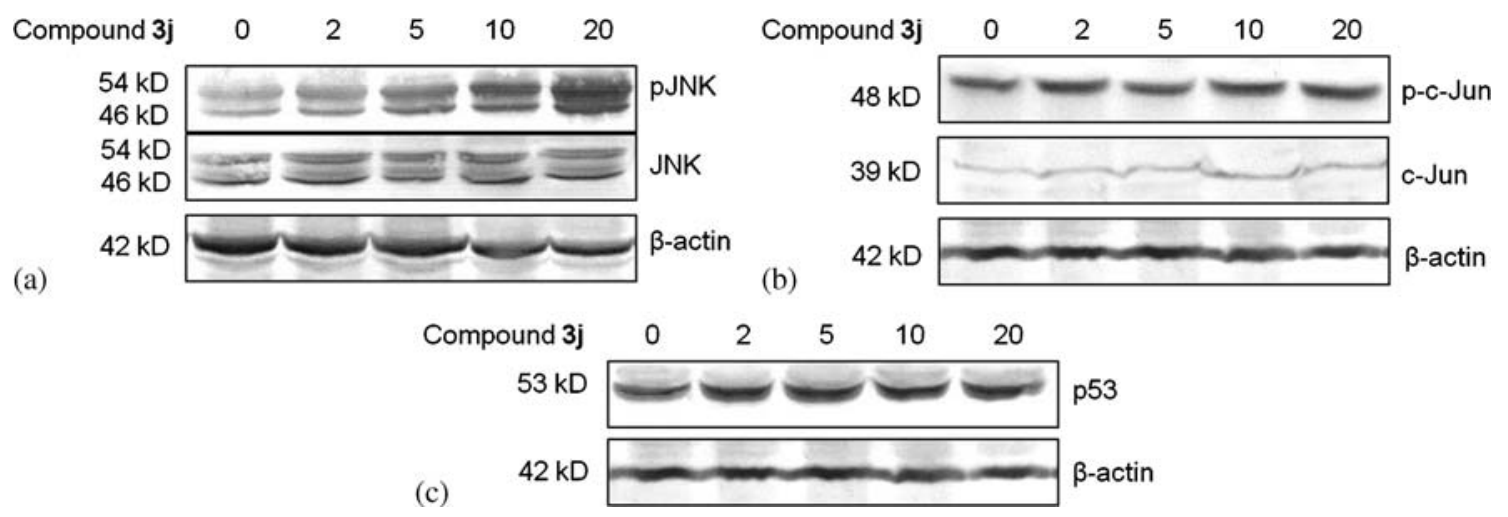

Figure 6. Protein expression analysis by Western Blots showing the expressions of A) JNK and pJNK: its downstream target; B) c-Jun and p-c-Jun and C) the tumor suppressor protein p53.

pathway of apoptosis, and caspase 3 are considered as crucial enzymes for programmed cell death. The treatment of $\mathbf{3 j}$ showed a significant rise in the apoptotic induction of germ cells. The redox status inside the cell is important for correct functioning of several enzymes, and can be used to alter enzyme activity. Thus, the alteration of redox status could act as a signaling mechanism. It may either trigger or block the apoptotic cell death programme depending on the severity of the oxidative stress. Similarly, apoptosis has been observed to be associated with a rise in oxidative stress depicted by an increase in lipid peroxidation and decline in

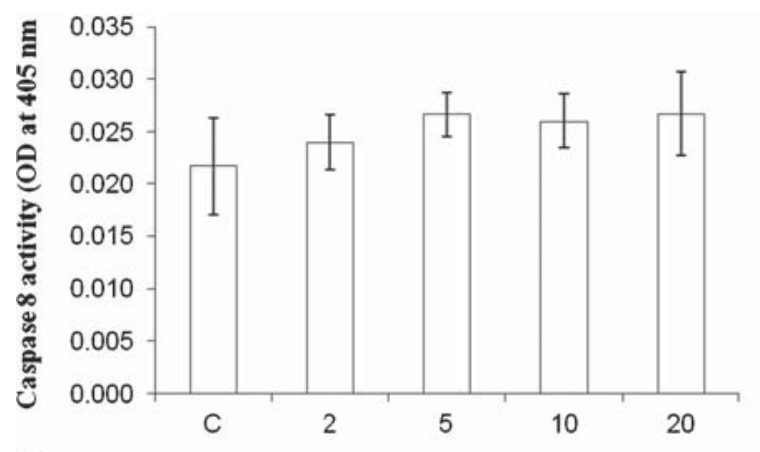

(a) 3j Conc $(\mu \mathrm{M})$ cellular activity of Catalase, GST and SOD. ${ }^{14}$ This is quite similar to the apoptotic response of germ cells induced by $\mathrm{H}_{2} \mathrm{O}_{2}$. In the present study, caspases were identified as important participants in the apoptotic induction of testicular germ cells. Based on the results, the intrinsic pathway involving caspase 9 and 3 was recognised to be responsible for the activity. It was recognized that p53 induced apoptosis results from cellular redox alterations. The redox alterations with elevated oxidative stress induced genotoxic stress and this genotoxic stress might affect p53 tumor suppressor gene/protein. Moreover, p53 represents the sensor of

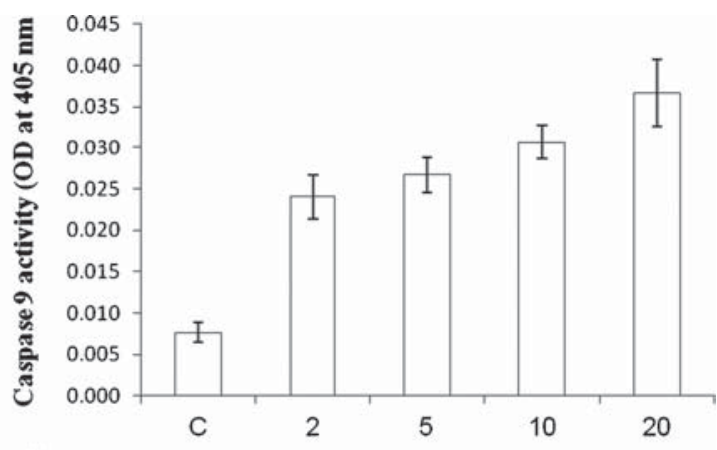

(b) 3j Conc $(\mu \mathrm{M})$

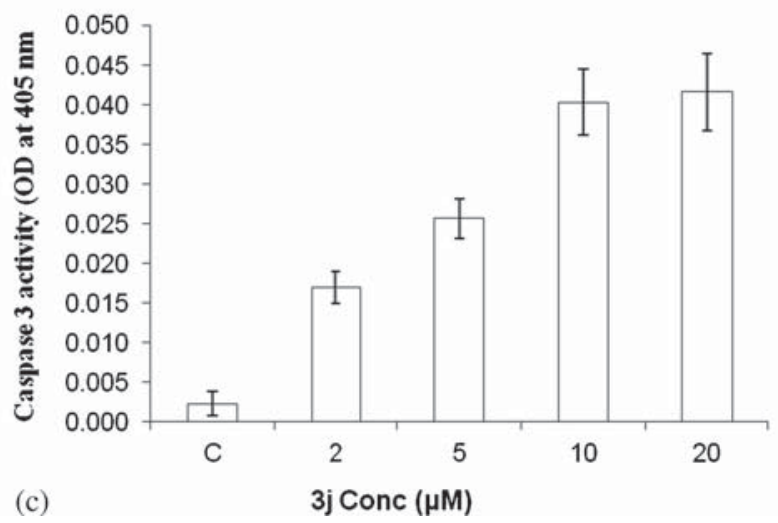

Figure 7. Graph showing caspase activities of treated germ cells with $2-20 \mu \mathrm{M}$ concentration of $\mathbf{3 j}$. A) Caspase 8; B) Caspase 9; C) Caspase 3. 
DNA damage whose activation provides an opportunity to repair any cellular damage prior to commitment to undergo apoptosis. ${ }^{56}$

We studied changes in the caspase protein and mRNA expression and their activities in induced germ cells. The activity of caspase 9 and 3 was found to be significantly $(\mathrm{p}<0.01)$ elevated in the treated cells (Figure 7B, C). Caspase 9 protein and its mRNA expression were also found upregulated which supports the intrinsic/mitochondrial pathway of apoptosis in the testicular germ cells treated with $\mathbf{3 j}$ (Figure 8A, B). The activity of caspase 8 , protein expression coincided well with the static and insignificant levels $(p>0.05)$ of their specific transcripts, which indicated that the course of signal transduction is not through extrinsic/death receptor pathway (Figure 8A). The treatment of $\mathbf{3 j}$ to germ cells have also induced an increase in the cleavage of the DNA repair protein poly-ADP-ribose polymerase (PARP) along with the increased activity of caspase 9 and 3 (Figure 8A). In the enzymatic analysis, the treatment of 10 and $20 \mu \mathrm{M}$ concentration of $\mathbf{3 j}$ to germ cells afforded comparable results, not being significantly different with respect to each other. These findings clearly indicated that phthalimide $\mathbf{3} \mathbf{j}$ is induced the oxidative stress by unbalancing the cellular redox status caused by cellular membrane lipid peroxidation and diminishing the antioxidant enzyme activities. The change in the redox status altered the mitochondrial permeability and activating caspase 9, which in-turn activated caspase-3. This resulted in the degradation of the repair protein PARP and finally led to apoptosis. Besides, MAP kinases were also observed to be activated primarily by cytokines or exposure to the extracellular stress including $\mathrm{H}_{2} \mathrm{O}_{2}$ or any other inducer like modified phthalimide $3 \mathbf{j}$. Based on our studies, the mediators of stress viz. JNK and p38 MAPKs were found as important for inducing the signals, and oxidative stress could be responsible for the activation of MAPKs, which ultimately leads to apoptosis.

Interestingly, the results of the current investigation are comparable with the recent reports of piperazine derivatives as apoptotic inducers. ${ }^{23,24}$

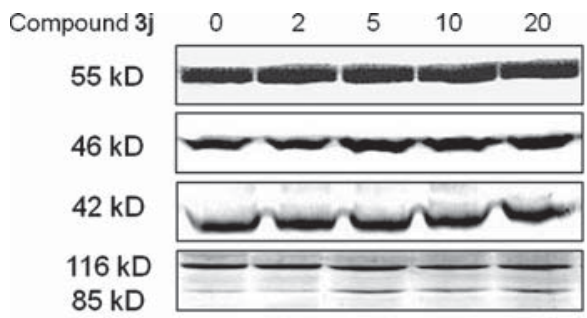

(a)

Figure 8. Caspase 8 and 9 expression levels in testicular germ cells treated with $2-20 \mu \mathrm{M}$ concentration of $\mathbf{3 j}$. A) Protein expression by Western blotting; B) Transcript levels by RT-PCR.

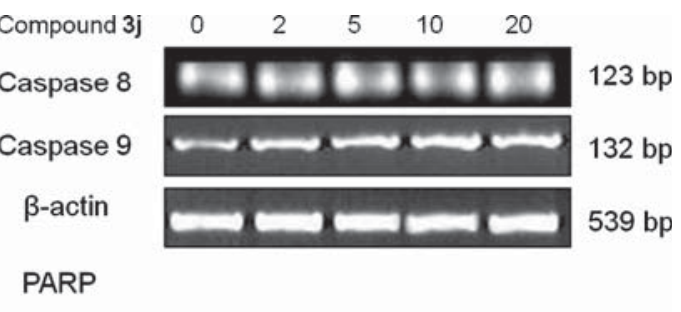

(b) 3.2e Effect of the most promising phthalimides regarding apoptosis on the in vitro viability of cancer cell lines: After verifying that phthalimides had an apoptotic action in testicular germ cells, their cytotoxic effect over cancer cells in culture was also evaluated. For these assays, the best five phthalimides regarding apoptotic action (3b, 3f, 3j, 3m \& $\mathbf{3 p}$ ) were chosen, together with CAL-72 (from a human sarcoma) and MCF-7 (from a human breast cancer) cell lines. The cells were cultured in the presence of compound in concentrations ranging from $1 \mu \mathrm{M}$ to $100 \mu \mathrm{M}$. Cytotoxicity was indirectly determined by measuring the metabolic activity of cells using the resazurin reduction assay. The cytotoxicity behaviour of the five compounds is summarized in Figure 9, Figure 10 and Table 2. The results showed that the five compounds had similar behaviour in both cells lines and allowed their classification into 3 groups: inactive (those compounds that do not show activity in the range of concentrations tested; this was the case of compound $\mathbf{3 m}$ having in the position $\mathrm{C}$ 2 the $t$-butyl group), cytostatic (those compounds that retard cell activity/multiplication in the range of concentrations tested; this was the case of compounds $\mathbf{3 b}$, 3f and $\mathbf{3 j}$ having in the position C-2 the benzyl group) and cytotoxic (those compounds that are toxic for cells; this was the case of compound $\mathbf{3 p}$ having in the position $\mathrm{C}-2$ the sec-butyl group; compound $\mathbf{3 p}$ showed identical $\mathrm{IC}_{50}$ values for both cell lines). Interestingly, although all compounds were capable of inducing significant apoptotic cell death in testicular germ cells when used at the concentration of $10 \mu \mathrm{M}$, only compound $\mathbf{3 p}$ was efficient in killing cancer cells in vitro.

\subsection{Molecular Docking vs. Apoptotic Activity}

The observations of enzymatic assays were validated with the aid of molecular docking studies of phthalimide $\mathbf{3 j}$ with caspases. The docking studies were conducted using Glide-XP protocol and the results are depicted in Table S1 (see Supporting Information). The binding affinity estimates were calculated for $\mathbf{3 j}$ against all seven caspase proteins. In comparison to other 


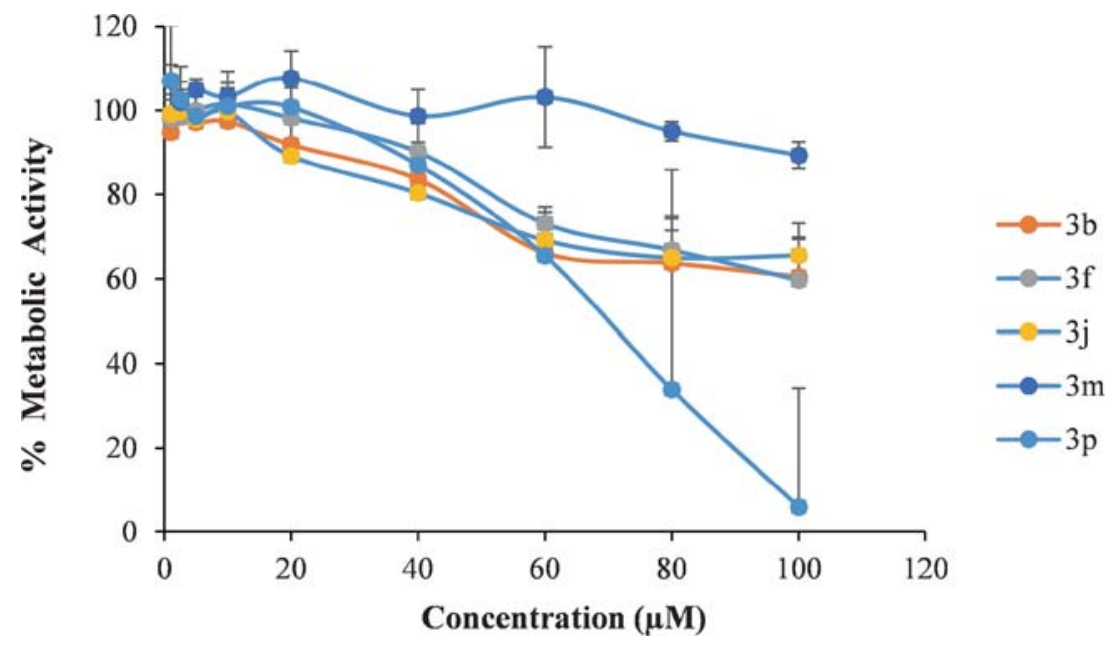

Figure 9. Metabolic activity of CAL-72 cells exposed to different concentrations of compounds $\mathbf{3 b}, \mathbf{3 f}, \mathbf{3} \mathbf{j}, \mathbf{3} \mathbf{m}$ and $\mathbf{3 p}$ (percentage in relation to the control). The bars represent the standard deviation of the average value obtained from 3 independent experiments.

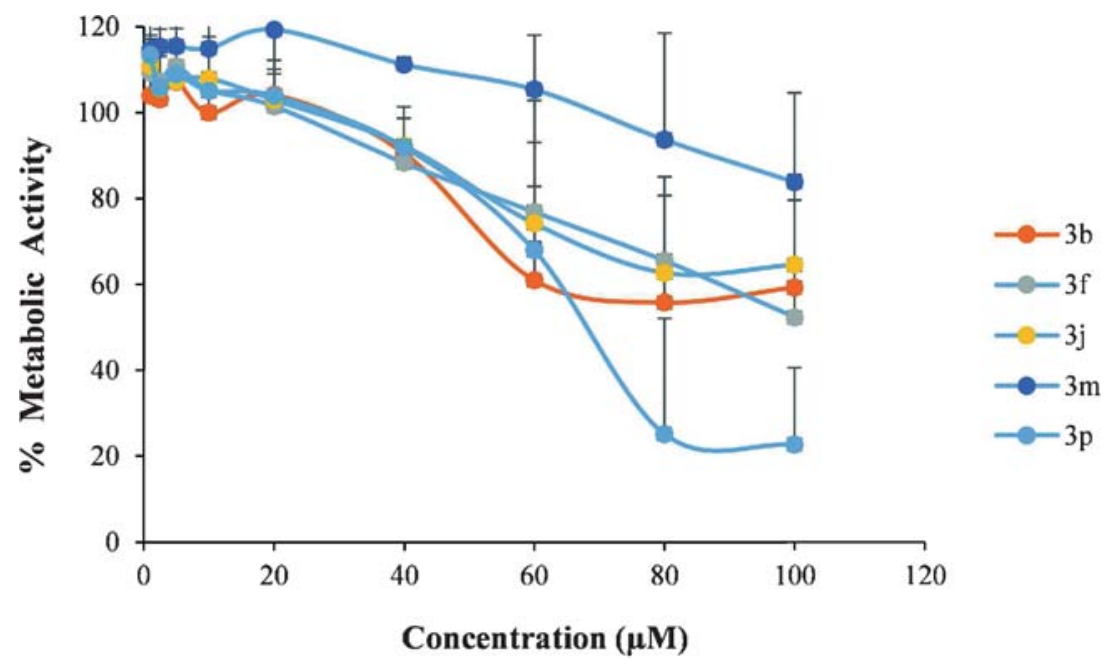

Figure 10. Metabolic activity of MCF-7 cells exposed to different concentrations of compounds $\mathbf{3 b}, \mathbf{3 f}, \mathbf{3 j}, \mathbf{3} \mathbf{m}$ and $\mathbf{3 p}$ (Percentage in relation to the control). The bars represent the standard deviation of the average value obtained from 3 independent experiments.

Table 2. Effect of compounds $\mathbf{3 b}, \mathbf{3 f}, \mathbf{3 j}, \mathbf{3} \mathbf{m}$ and $\mathbf{3 p}$ on the viability of CAL-72 and MCF-7 cancer cell lines.

\begin{tabular}{lcc}
\hline Compound & CAL-72 & MCF-7 \\
\hline $\mathbf{3 b}$ & Cytostatic & Cytostatic \\
$\mathbf{3 f}$ & Cytostatic & Cytostatic \\
$\mathbf{3 j}$ & Cytostatic & Cytostatic \\
$\mathbf{3 m}$ & Inactive & Inactive \\
$\mathbf{3 p}$ & Cytotoxic $\left(\mathrm{IC}_{50}=70 \mu \mathrm{M}\right)$ & Cytotoxic $\left(\mathrm{IC}_{50}=68 \mu \mathrm{M}\right)$ \\
\hline
\end{tabular}

caspases, ligand binding analyses with caspase 3 (3KJF) displayed a high Glide XP score of $-4.32 \mathrm{kcal} / \mathrm{mol}$ with binding free energy score $(\Delta \mathrm{G}),-67.71 \mathrm{kcal} / \mathrm{mol}$. Phthalimide 3j was observed to exhibit the close contacts with residues -His121 and Trp206, which have been proved experimentally as interacting sites for ligand binding in caspase 3 (Figure 11). We also observed a significant $\Delta \mathrm{G}$ score, $-66.13 \mathrm{kcal} / \mathrm{mol}$ for caspase 


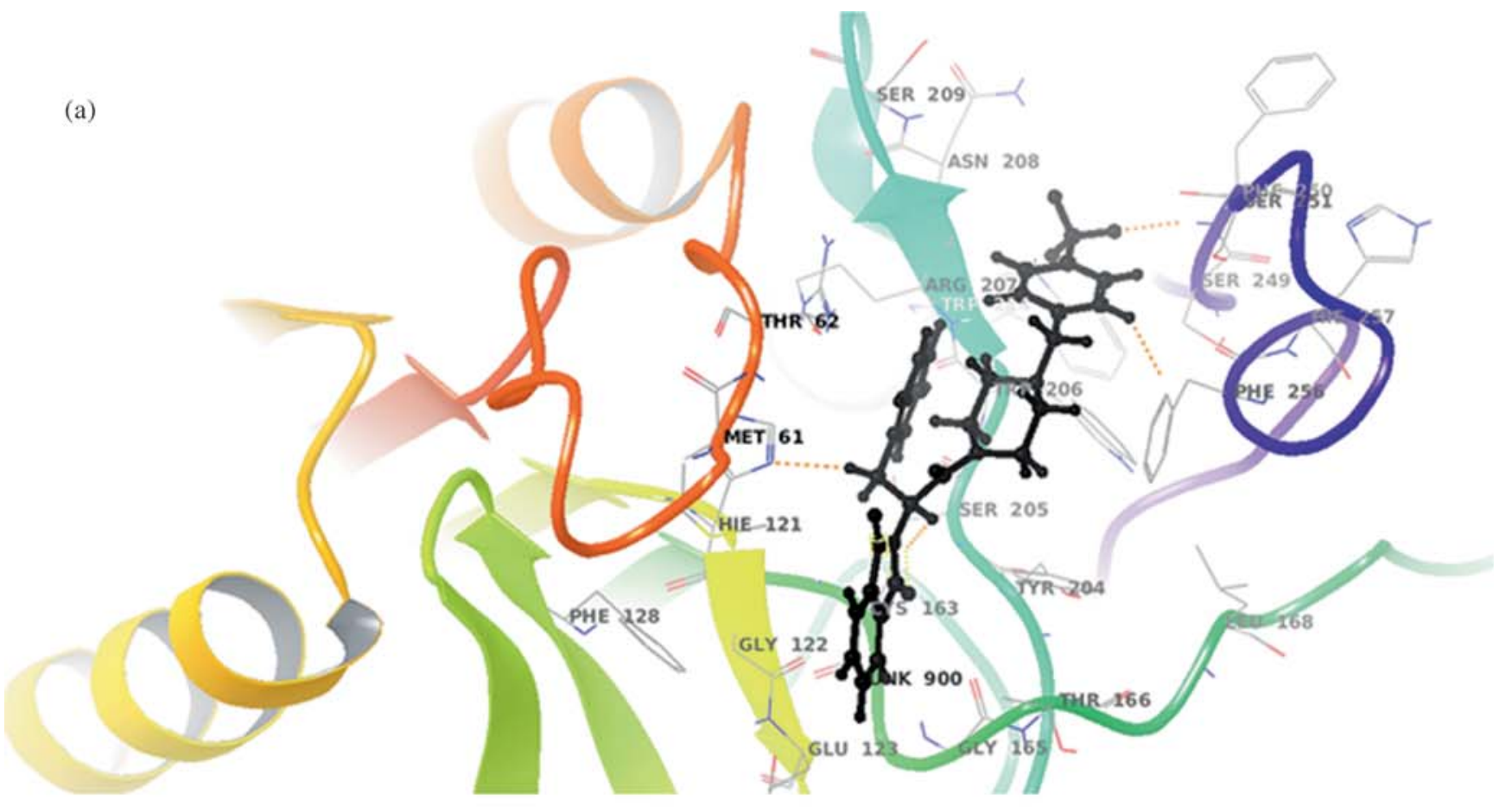

(b)

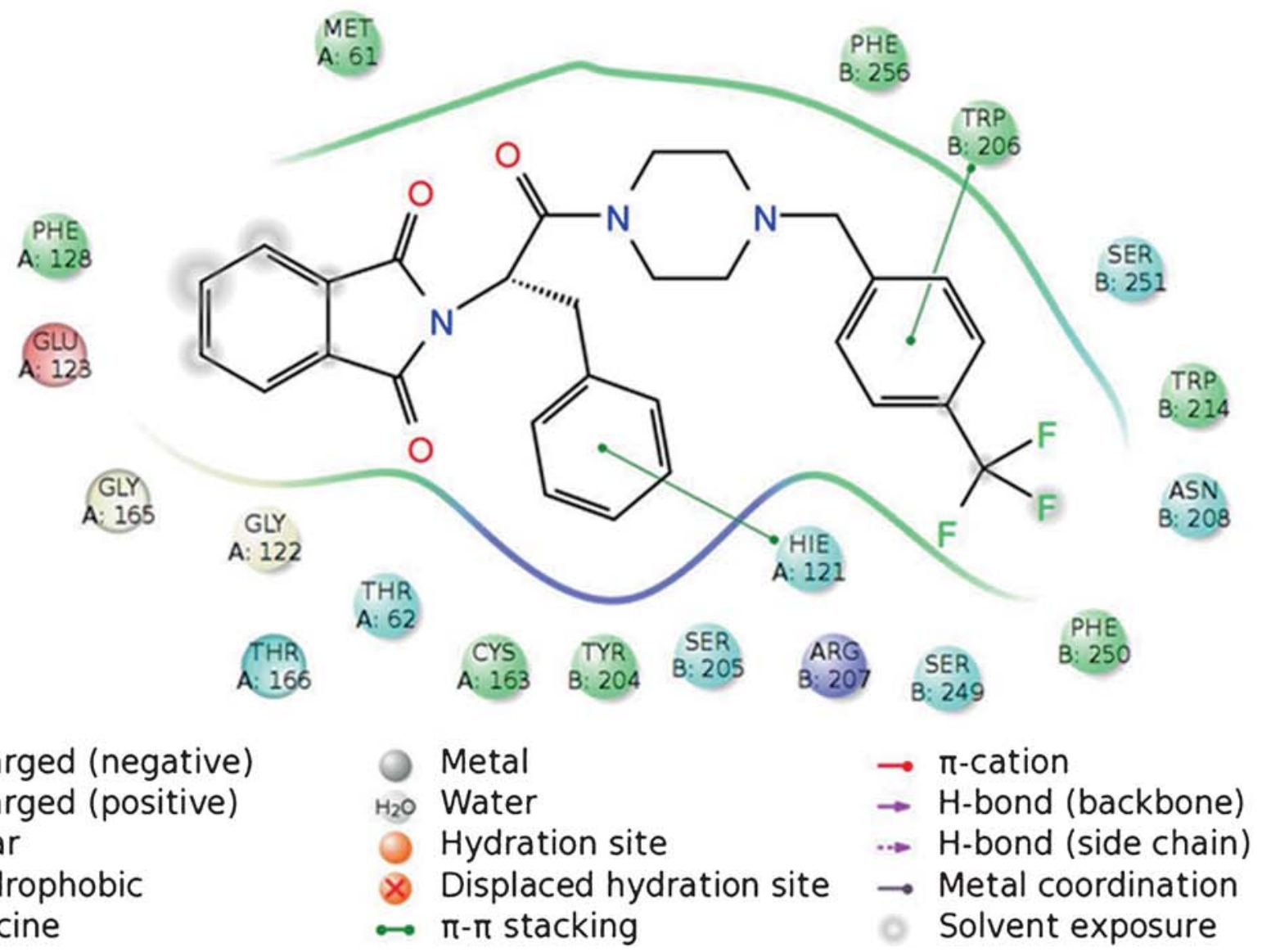

Figure 11. Interaction diagram of phthalimide $\mathbf{3 j}$ and CASP3. A) A close-up view of $\mathbf{3 j}$ binding sites in CASP3 structure: marked residues are mostly involved in the ligand interactions; B) 2D plot representation of the ligand-protein interaction diagram: color represented different types of residues and bonding important for the interactions. 
9 (2AR9) and observed a couple of potential contacts with phthalimide $\mathbf{3 j}$ (Figure 12). A significantly strong protein-ligand interaction was observed between the residue Arg355 and $\mathbf{3 j}$. In addition, the residues Trp354, Thr179, Arg180 and Thr181 also emerged as important sites for ligand binding in caspase 9. We observed a significant $\Delta \mathrm{G}$ score $(-66.54 \mathrm{kcal} / \mathrm{mol})$ but a low glide score $(-2.34 \mathrm{kcal} / \mathrm{mol})$ for caspase 7 (4JR2) that indicated the poor contacts with $\mathbf{3 j}$. Studies revealed that caspase 2 and caspase 3 possess identical residues at loop 4, which helps in the active receptor binding mechanism. ${ }^{58,59}$

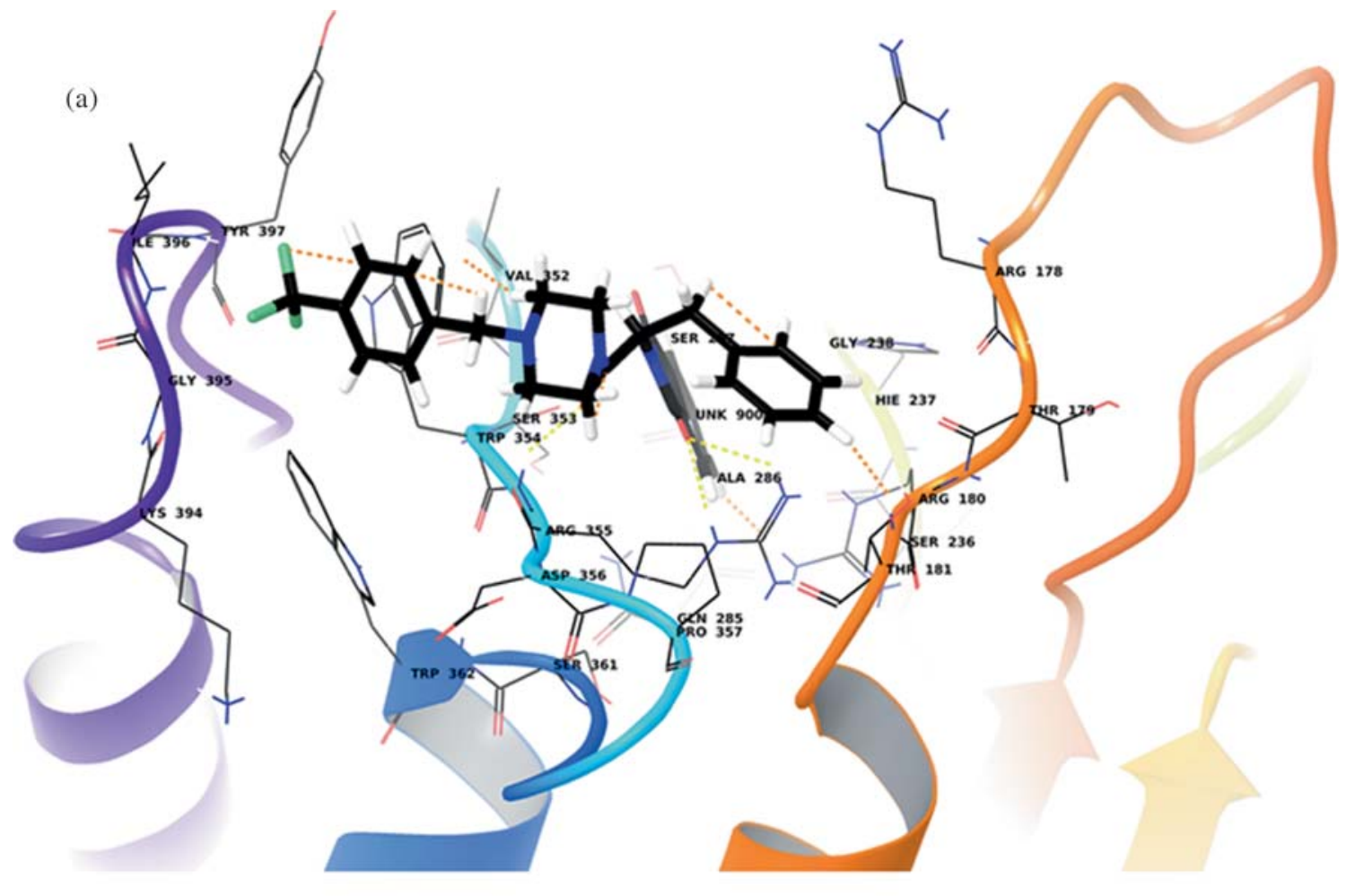

(b)

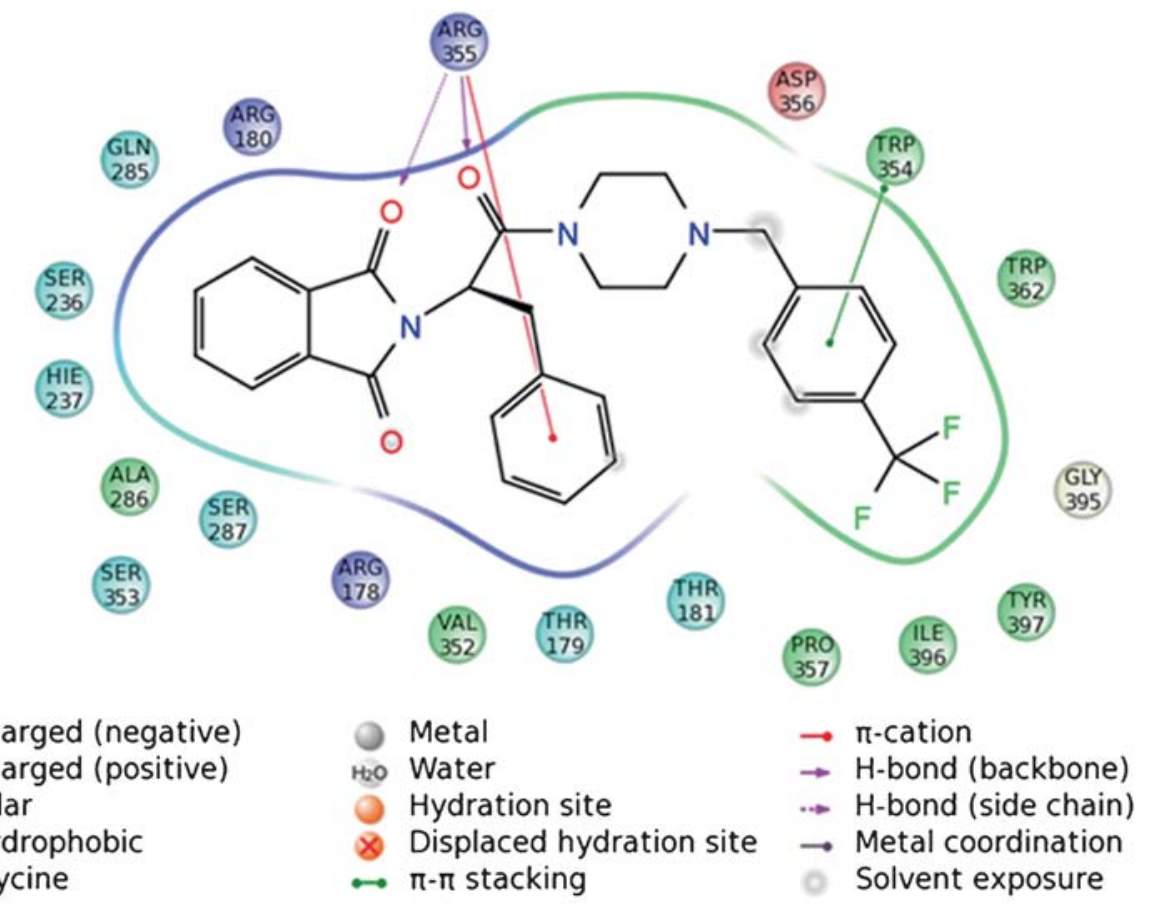

Figure 12. Interactions diagram for $\mathbf{3 j}$ ligand and CASP9. A) Highlighted residues in CASP9 structure formed close contact with $\mathbf{3 j}$ ligand during docking; B) 2D plot representation of the ligand-protein interaction diagram: color represented different types of residues and bonding important for the interactions. 


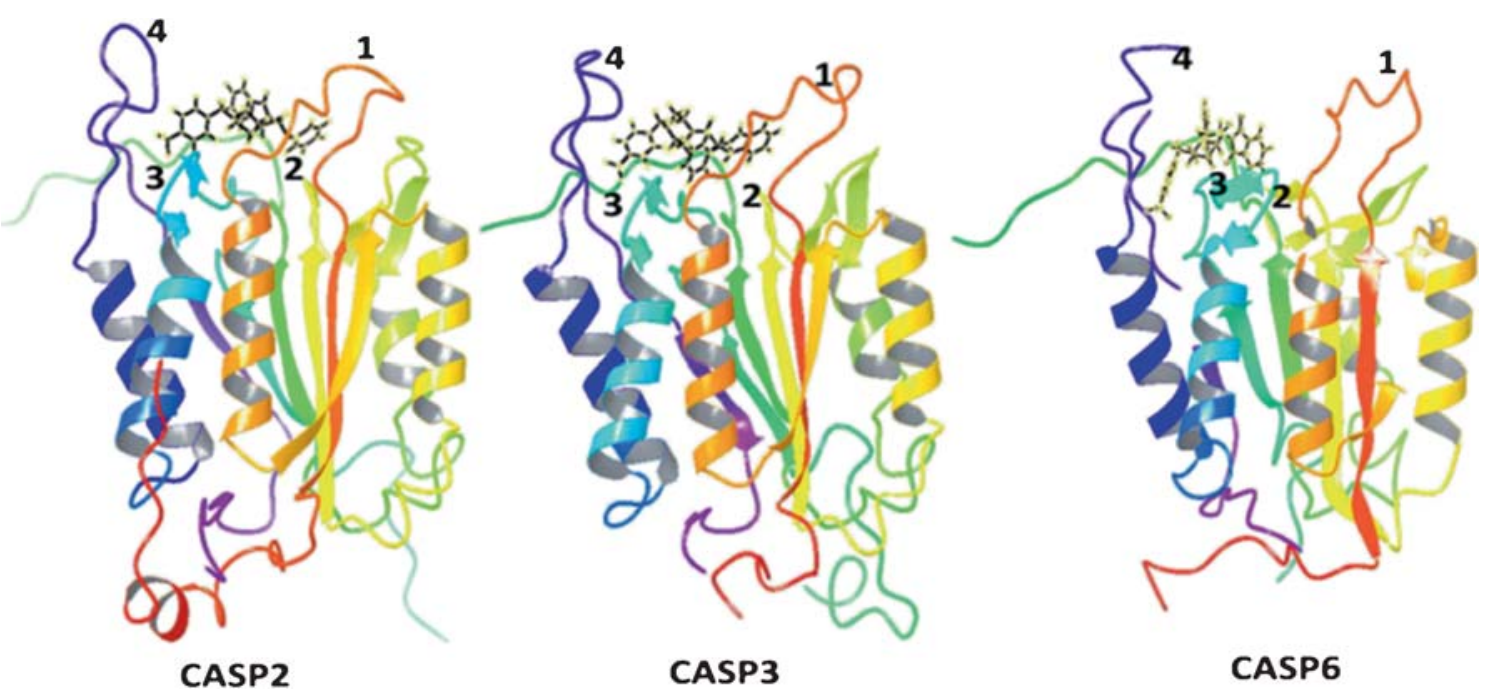

Figure 13. A comparative view of dock poses for three different caspases. Interactions of $\mathbf{3 j}$ (ball-stick conformation) in the active site of three different caspases (caspase 2, caspase 3 and caspase 6). The numbers 1 to 4 indicate the loops. The loop 4 regions are longer in caspase- 2 and 3 . The structures are in ribbon representation and rainbow coloring.

A close interaction of many residues in the active sites of caspase 3 was advocated by docking results of caspase 2 and caspase 6 (Figure 13). Furthermore, all the tautomers of $\mathbf{3 j}$ ligand showed a potentially higher $\Delta \mathrm{G}$ score when docked against these three proteins.

\section{Conclusions}

Apoptosis plays a significant role in the development of normal cells and tissues. Apoptosis inducers are considered as potential contenders for the development of anticancer chemotherapeutics. The current study presents a novel class of phthalimides functionalized with arylpiperazines as significant inducers of apoptosis. The functionalization of arylpiperazines at the para position was observed as a crucial step for the significant apoptotic response. Phthalimide $3 \mathbf{j}$ possessing benzyl substituent at the C-2 position and the 4-trifluorobenzyl substituent at the fourth position of piperazine was classified as a strong apoptotic inducer. The apoptotic potency of new phthalimides was further confirmed by TUNEL assay, fluorescence assay observing the cleavage of DNA, caspase activities and various proapoptotic protein/mRNA expression analyses. Our study advocated phthalimide $\mathbf{3 j}$ as a significant inducer for primary testicular germ cell apoptosis, and data suggested that it may be a potential molecule in the search for new therapeutic agents. The current studies also demonstrated that structure-based design of these new molecules is the crucial phase for the future discovery of new anticancer agents. Further, clinicians and $\mathrm{R} \& \mathrm{D}$ companies may extrapolate the phthalimide system for the design of potent and efficient anticancerous apoptotic agents, which might be beneficial to the public health system.

\section{Supplementary Information (SI)}

All additional information relating to characterization of the compounds such as ${ }^{1} \mathrm{H}$ and ${ }^{13} \mathrm{C}$ NMR spectra (Figures S1-S40), 2-D NMR spectra (Figures S41-S43), Images of CAL-72 and MCF-7 cells after incubation of compound (Figure S44), Docking results of $\mathbf{3 j}$ ligand interacting with seven human caspases (Table TS1) and Primer-specific conditions used for PCR amplification of candidate genes (Table TS2) are given in the supporting information, available at www.ias.ac.in/ chemsci.

\section{Acknowledgements}

BR is grateful to the Department of Science and Technology, Ministry of Science and Technology, India for financial support (SR/FT/CS-108/2010) and the University of Delhi for instrument facility. AKS and YK are grateful to CSIR and UGC for providing SRF. NL acknowledges the support and funding from Department of Biotechnology, BTISnet, Govt. of India. AL, HT and JR recognize the support of FCT - Fundação para a Ciência e a Tecnologia -, under CQM grant PEst-OE/QUI/UI0674/2014 (CQM is a FCT - National Research Unit). BR and JR acknowledge the additional support of the Bilateral Agreement between India (INT/ PORTUGAL/P-17/2013) and Portugal (FCT/DST 2013/ 2015 - Ref. 441.00). 


\section{References}

1. Reed J C and Tomaselli K J 2000 Curr. Opin. Biotechnol. 11586

2. Saraste A and Pulkki K 2000 Cardiovasc. Res. 45528

3. Igney F H and Krammer P H 2002 Nat. Rev. Cancer. 2 277

4. Meier P, Finch A and Evan G 2000 Nature 407796

5. Hashimoto K, Saito B, Miyamoto N, Oguro Y, Tomita D, Shiokawa Z, Asano M, Kakei H, Taya N, Kawasaki M, Sumi H, Yabuki M, Iwai K, Yoshida S, Yoshimatsu M, Aoyama K, Kosugi Y, Kojima T, Morishita N, Dougan D R, Snell G P, Imamura S and Ishikawa T 2013 J. Med. Chem. 561228

6. Hengartner M O 2000 Nature 740770

7. Wang Y, Zhang X, Zhao J, Xie S and Wang C $2012 \mathrm{~J}$. Med. Chem. 553502

8. Reed J C 1999 J. Clin. Oncol. 172941

9. Robertson G S, Crocker S J, Nicholson D W and Schulz J R B 2000 Brain Pathol. 10283

10. Riedl S J and Shi Y 2004 Nat. Rev. Mol. Cell Biol. 5897

11. Okada H and Mak T W 2004 Nat. Rev. Cancer 4592

12. Kim R, Tanabe K, Uchida Y, Emi M, Inoue H and Toge T 2002 Cancer Chemother. Pharmacol. 50343

13. Porter A G and Jänicke R U 1999 Cell Death Differ. 699

14. Maheshwari A, Misro M M, Aggarwal A, Sharma R K and Nandan D 2009 FEBS J. 276870

15. Maheshwari A, Misro M M, Aggarwal A and Sharma R K 2012 Apoptosis 17551

16. Zhang H Z, Kasibhatla S, Wang Y, Herich J, Guastella J, Tseng B, Drewe J and Cai S X 2004 Bioorg. Med. Chem. 12309

17. Kok S H, Gambari R, Chui C H, Yuen M C, Lin E, Wong R S, Lau F Y, Cheng G Y, Lam W S, Chan S H, Lam $\mathrm{K} \mathrm{H}$, Cheng C H, Lai P B, Yu M W, Cheung F, Tang J C and Chan A S 2008 Bioorg. Med. Chem. 163626

18. Lv H S, Kong X Q, Ming Q Q, Jin X, Miao J Y and Zhao B X 2012 Bioorg. Med. Chem. Lett. 22844

19. Sodeoka M, Dodo K, Teng Y, Iuchi K, Hamashima Y, Iwasa E and Fujishiro S 2012 Pure Appl. Chem. 841369

20. Liu Y, Chen T, Liu J and Wong Y S 2013 Med. Chem. Comm. 4865

21. Chopra A, Anderson A and Giardina C 2014 J. Biol. Chem. 2892978

22. Chung K S, Han G, Kim B K, Kim H M, Yang J S, Ahn J, Lee K, Song K B and Won M 2013 Cancer Chemother. Pharmacol. 721315

23. She E X and Hao Z 2013 Am. J. Transl. Res. 5622

24. Sampson J J, Donkor I O, Huang T L and Adunyah S E 2011 Int. J. Biochem. Mol. Biol. 278

25. Xue D Q, Zhang X Y, Wang C J, Ma L Y, Zhu N, He P, Shao K P, Chen P J, Gu Y F, Zhang X S, Wang C F, Ji C H, Zhang Q R and Liu H M 2014 Eur. J. Med. Chem. 85235

26. Yu Z, Wang R, Xu L, Xie S, Dong J and Jing Y 2011 PLoS One $\mathbf{6}$ e 15843

27. Kim B K, Kim D M, Chung K S, Park S K, Choi S J, Song A, Lee K, Lee C W, Song K B, Han G, Simon J, Kim H M and Won M 2011 New Drugs 29853

28. Brossard D, Lechevrel M, El Kihel L, Quesnelle C, Khalid M, Moslemi S and Reimund J M 2014 Eur. J. Med. Chem. 86279

29. Eriksson T, Björkman S and Höglund P 2001 Eur. J. Clin. Pharmacol. 57365
30. Sano H, Noguchi T, Miyajima A, Hashimoto $\mathrm{Y}$ and Miyachi H 2006 Bio. Med. Chem. Lett. 163068

31. D'Amato R J, Loughnan M S, Flynn E and Folkman J 1994 Proc. Natl. Acad. Sci. 914082

32. Stewart A K 2014 Science $\mathbf{3 4 3} 256$

33. Sherbet G V 2015 Anticancer Res. 355767

34. Shiheido H, Terada F, Tabata N, Hayakawa I, Matsumura N, Takashima H, Ogawa Y, Du W, Yamada T, Shoji M, Sugai T, Doi N, Iijima S, Hattori Y and Yanagawa H 2012 PloS One 7 e38878

35. Shah N P, Tran C, Lee F Y, Chen P, Norris D and Sawyers C L 2004 Science 305399

36. Puttini M, Coluccia A M L, Boschelli F, Cleris L, Marchesi E, Donella-Deana A, Ahmed S, Redaelli S, Piazza R, Magistroni V, Andreoni F, Scapozza L, Formelli F and Gambacorti-Passerini C 2006 Cancer Res. 6611314

37. Singh A K, Rathi B, Medviediev V V, Shishkin O V, Bahadur V, Singh T, Singh B K, Vijayan N, Balachandran V and Gorobets N Y 2016 J. Chem. Sci. 128297

38. Chandak N, Bhardwaj J K, Sharma R K and Sharma P K 2013 Eur. J. Med. Chem. 59203

39. Pearse A E 1968 In Histochemistry: Theoretical and Applied $2^{\text {nd }}$ edn. (London: J \&A Churchill)

40. Sharma R K and Bhardwaj J K 2009 J. Microsc. 236236

41. Sharma R K, Sharma V and Bhardwaj J K 2011 J. Adv. Microsc. Res. 6223

42. Ohkawa H, Ohishi N and Yagi K 1979 Anal. Biochem. 95351

43. Das K, Samanta L and Chainy G B N 2000 Indian J. Biochem. Biophys. 37201

44. Aebi H 1984 Meth. Enzymol. 105121

45. Habig W, Pabst M and Jakoby W 1974 J. Biol. Chem. 2497130

46. Bradford M M 1976 Anal. Biochem. 72248

47. Zor T and Selinger Z 1996 Anal. Biochem. 236302

48. Friesner R A, Murphy R B, Repasky M P, Frye L L, Greenwood J R, Halgren T A, Sanschagrin P C and Mainz D T 2006 J. Med. Chem. 496177

49. Berman H M, Westbrook J, Feng Z, Gilliland G, Bhat T N, Weissig H, Shindyalov I N and Bourne P E 2000 Nucleic Acids Res. 28235

50. Maestro, version 9.3, Schrödinger L L C 2012 New York

51. LigPrep, version 2.5, Schrödinger L L C, 2012 New York

52. Eldridge M D, Murray C W, Auton T R, Paolini G V and Mee R P 1997 J. Comput.-Aided Mol. Des. 31 425

53. Rastelli G, Del Rio A F, Degliesposti G F and Sgobba M 2010 J. Comput. Chem. 31797

54. Furniss B S, Hannafold A J, Smith P W G and Tatchell A R 1989 In Vogel's Textbook of Practical Organic Chemistry $5^{\text {th }}$ edn. (London: Longman Scientific and Technical)

55. Townsend D M and Tew K D 2003 Oncogene 227369

56. Carmody R J and Cotter T G 2001 Redox Rep. 677

57. Maheshwari A, Misro M M, Aggarwal A, Sharma R K and Nandan D 2011 Mol. Reprod. Dev. 7869

58. Fang B 2009 In Structural Basis of Caspase-3 Substrate Specificity Revealed by Crystallography, Enzyme Kinetics and Computational Modelling PhD Dissertation (Atlanta, Georgia, United States: Georgia State University)

59. Nicholson D W 1999 Cell Death Differ. 61028 